\title{
Sexual and reproductive health of young people in India: A review of policies, laws and programmes
}

Shireen J. Jejeebhoy

Population Council

K.G. Santhya

Population Council

Follow this and additional works at: https://knowledgecommons.popcouncil.org/departments_sbsr-pgy

Part of the Demography, Population, and Ecology Commons, Family, Life Course, and Society

Commons, Gender and Sexuality Commons, International Public Health Commons, and the Women's

Health Commons

How does access to this work benefit you? Let us know!

\section{Recommended Citation}

Jejeebhoy, Shireen J. and K.G. Santhya. 2011. "Sexual and reproductive health of young people in India: A review of policies, laws and programmes." New Delhi: Population Council. 
This paper synthesises the key policies, laws and programmes in India that focus on or have implications for the sexual and reproductive health and rights of young people. It includes a summary of what is known about the sexual and reproductive health situation of young people, an assessment of the salient features of current policies, laws and programmes, and a discussion of the extent to which these policies, laws and programmes have responded to the sexual and reproductive health needs of young women and men.

For additional copies of this report, please contact:

Population Council

Zone 5-A, Ground Floor

India Habitat Centre

Lodi Road

New Delhi -110003

Phone: 011-2464 2901/02

Email: info-india@popcouncil.org

Web site: http://www.popcouncil.org/asia/india/html

The Population Council is an international, non-profit, non-governmental organisation that seeks to improve the well-being and reproductive health of current and future generations around the world and to help achieve a humane, equitable and sustainable balance between people and resources. The Council conducts biomedical, social science and public health research, and helps build research capacities in developing countries.

\section{Copyright $(92011$ Population Council}

Suggested citation: S. J. Jejeebhoy and K. G. Santhya. 2011. Sexual and reproductive health of young people in India: A review of policies, laws and programmes. New Delhi: Population Council. 


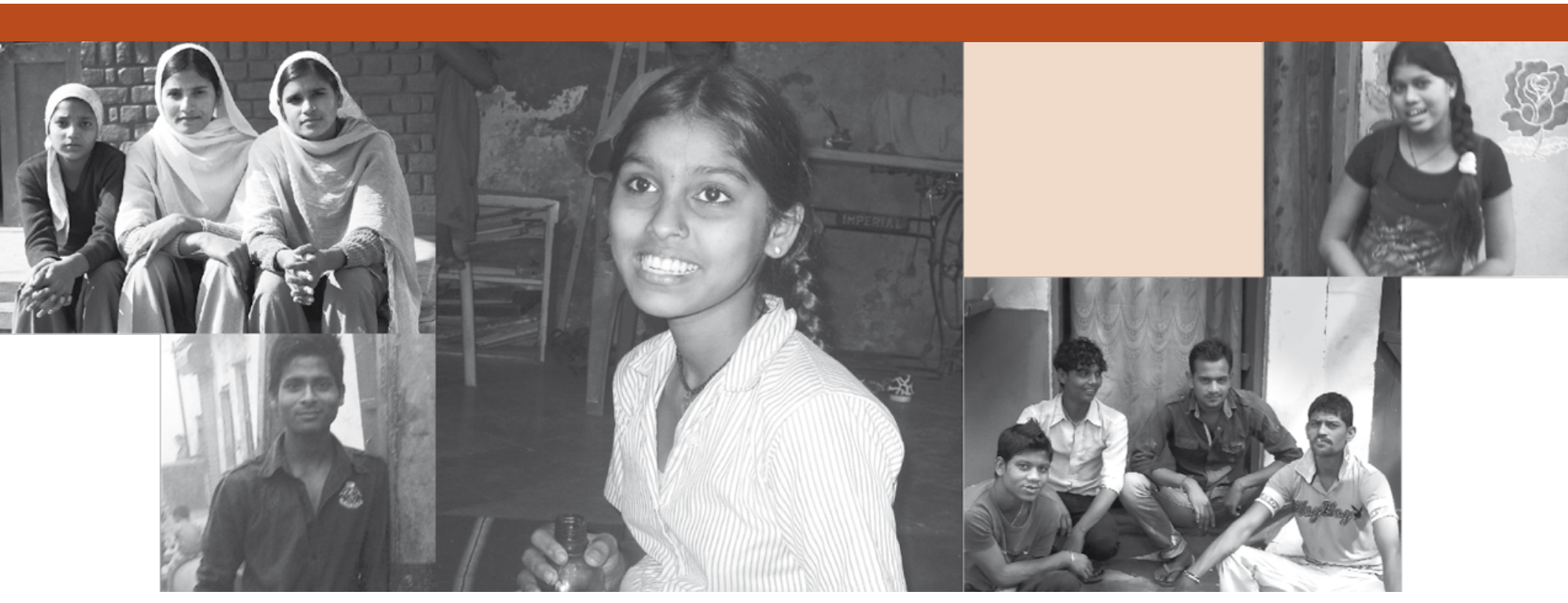

\section{Sexual and reproductive health of young people in India: A review of policies, laws and programmes}

Shireen J Jejeebhoy

K G Santhya 



\section{Contents}

Introduction

Methodology

The sexual and reproductive health situation of young people

Policy initiatives to address young people's sexual and reproductive health needs and rights

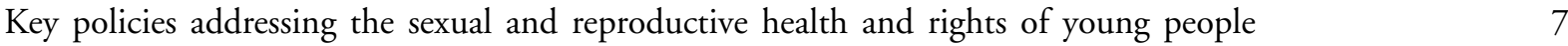

Key policies promoting empowerment, and gender equity and equality among young people 9

Key policies addressing the nutritional needs of young people $\quad 10$

Key policies addressing young people's education and skill-building needs $\quad 10$

Key policies addressing the need for building a supportive environment for young people 12

Gaps

Laws to address young people's sexual and reproductive health and rights

Prohibition of Child Marriage Act 2006

Protection of Women from Domestic Violence Act 2005

The Immoral Traffic (Prevention) Amendment Bill 2006

The Protection of Children from Sexual Offences Bill 2011

Medical Termination of Pregnancy Act (MTP) 1971 and Amendment of 2002

The Right of Children to Free and Compulsory Education Act 2009

Gaps

Programme initiatives to address young people's sexual and reproductive health needs and rights

Programmes to raise awareness about sexual and reproductive health issues

Programmes that facilitate access to sexual and reproductive health counselling and services

Programmes that address gender disparities and adolescent rights

Programmes that enhance nutrition among adolescent girls

Programmes that enable young people to attain a basic minimum level of education

and attain marketable skills

Programmes that build a supportive environment 


\section{List of table \& appendix}

Table 1: $\quad$ Sexual and reproductive health profile of young people, India

Appendix 1: Summary of policies and programmes addressing young people's sexual and reproductive health needs and rights 


\section{Acknowledgements}

This review has benefitted hugely from the input of many. We are grateful to the Ford Foundation for support, which made this study possible. We would also like to acknowledge the insightful comments and suggestions of Vanita Nayak Mukherjee, Programme Officer, Ford Foundation, on a previous draft of this report. Her comments have been incorporated in this report and are gratefully acknowledged.

We are grateful to several colleagues for their support and insights as we prepared this review. M.A. Jose was responsible for conducting a search of the literature relating to our topic; his support and success in identifying many of the wide range of articles and papers included in this review are much appreciated. Jyoti Moodbidri edited the report and we thank her for both her technical and editorial inputs. Komal Saxena was responsible for reviewing the manuscript and managing the preparation of this report; we are grateful to her for her meticulous attention to detail, which has made the report more readable and precise. 



\section{CHAPTER 1}

\section{Introduction}

Today, about 358 million people in India-nearly one-third of the country's population-are young people aged 10-24 (Office of the Registrar General and Census Commissioner, India, 2006). It is increasingly recognised that whether India achieves the Millennium Development Goals, whether it achieves its population stabilisation objectives and whether it can realise the advantage of its demographic dividend, will depend on the nation's investment in its young people. Compared to earlier generations, the situation of young people in India has undoubtedly improved: they are healthier and better educated than ever before, and gender disparities in child mortality, school enrolment and educational attainment have narrowed. Nonetheless, many obstacles exist that inhibit young people from making informed life choices and from adopting egalitarian notions of masculinity and femininity, limit young women's exercise of agency, and compromise young people's health, notably in the sexual and reproductive health arena.

There are, however, some encouraging signals. One of these is the political commitment for meeting the sexual and reproductive health needs of young people. For example, India has articulated its commitment to promoting and protecting the sexual and reproductive health and rights of young people through numerous policies and programmes, particularly over the last decade and a half. The National Population Policy 2000, the National AIDS Prevention and Control Policy 2002, the National Youth Policy 2003, and the National Adolescent
Reproductive and Sexual Health Strategy are key examples of the recognition that the sexual and reproductive health needs and rights of young people require urgent attention.

This paper synthesises the key policies, laws and programmes in India that focus on or have implications for the sexual and reproductive health and rights of young people. We begin with a summary of what is known about the sexual and reproductive health situation of young people. We then present a synthesis of the salient features of current policies, laws and programmes, and explore the extent to which these policies, laws and programmes have responded to the sexual and reproductive health needs of young women and men. We focus on a number of thrust areas, namely, raising young people's awareness about reproductive and sexual health matters, facilitating their access to reproductive and sexual health counselling and services, addressing gender disparity, and supplementing nutrition. In view of the linkages between educational attainment, acquisition of livelihood skills and gainful employment of young people and their achievement of good sexual and reproductive health as also the realisation of their sexual and reproductive rights, we also focus on policies, laws and programmes that enable young people to acquire higher educational levels and relevant marketable skills. Finally, we include a discussion of policies and programmes that articulate the need for building a supportive environment for young people. 


\section{Methodology}

Given our objective of synthesising available policies, laws and programmes, this paper relies heavily on an earlier monograph we had authored in 2007 that explored similar issues (Santhya and Jejeebhoy, 2007). It expands on what was contained in that monograph with a focus on changes that may have occurred in the intervening period. In preparing this paper, we reviewed various policies and vision documents pertaining to population, youth, health, HIV/AIDS prevention and control, women's empowerment, and education. At the national level, we reviewed policy documents that directly or indirectly address young people's sexual and reproductive health and rights and/or other aspects of their development. The policies reviewed were the National Youth Policy 2003 and the draft Youth Policy 2010 (under preparation), the National Health Policy 2002, the National AIDS Prevention and Control Policy 2002, the National Policy for the Empowerment of Women 2001, the National Population Policy 2000, the National Skill Development Policy 2009, and the National Policy on Education 1986 (as modified in 1992). We reviewed pertinent laws, including the Prohibition of Child Marriage Act 2006, the Protection of Women from Domestic Violence Act 2005, the Medical Termination of Pregnancy (MTP) Act 1971 and the Right to Education Act 2009. Additionally, we reviewed Five Year Plan documents, and various programme and strategy documents, including the National Adolescent Reproductive and Sexual Health Strategy, the National AIDS Control Programme Phase 3 Strategy and Implementation Plan, and the annual reports of various ministries, including those of the Ministries of Health and Family Welfare, Youth Affairs and Sports, Human Resource Development, and Women and Child Development.
We start by acknowledging the limitations of this paper. First, though programming for young people has a long history in India, our discussion mainly focuses on the policies and programmes initiated in the 1990s and thereafter. Second, while the focus of this paper is on programmes initiated by the government, we recognise that NGOs have played a significant role in articulating the sexual and reproductive health needs and rights of young women and men, and in designing programmes that respond to their diverse needs; the role of NGOs will be the focus of discussion of a separate paper. Third, while our purpose is to assess programmes intended to meet the needs of married and unmarried young people separately, we acknowledge that programmes have rarely distinguished between the married and the unmarried, or between married youth and adults. Finally, the lack of data on the reach of most programmes has hampered our discussion on the extent to which these programmes have succeeded in meeting the sexual and reproductive health needs of young people.

\section{The sexual and reproductive health situation of young people}

Evidence on the sexual and reproductive health situation of young people suggests that young people continue to have a wide array of unmet needs in the area of sexual and reproductive health (see Table 1).

\section{Early entry into sexual life}

First, entry into sexual life occurs at a young age for many. Although India is committed to protecting adolescents from such harmful traditional practices as early marriage, and despite laws prohibiting marriage to young women before age 18 and to young men before age 21 , marriage continues to take place in adolescence for significant proportions 


\section{Table 1:}

Sexual and reproductive health profile of young people, India

\begin{tabular}{|c|c|c|}
\hline & Young men & Young women \\
\hline \multicolumn{3}{|l|}{ Entry into sexual life } \\
\hline$\%$ young people aged $20-24$ married as children, i.e., by age $18^{1}$ & 10.0 & 47.4 \\
\hline$\%$ young people aged $15-24$ reporting pre-marital sex in adolescence ${ }^{2^{*}}$ & 11.0 & 4.9 \\
\hline \multicolumn{3}{|l|}{ Unsafe and unwanted sex } \\
\hline $\begin{array}{l}\% \text { married young women aged } 15-24 \text { currently practising contraception by self } \\
\text { or husband }{ }^{3}\end{array}$ & & 28.0 \\
\hline $\begin{array}{l}\% \text { married young women aged } 15-24 \text { currently using modern } \\
\text { non-terminal methods by self or husband }{ }^{3}\end{array}$ & & 11.0 \\
\hline $\begin{array}{l}\% \text { married young women aged } 15-24 \text { who had experienced sexual violence } \\
\text { within marriage }^{2}\end{array}$ & & 32.2 \\
\hline $\begin{array}{l}\% \text { young people aged } 15-24 \text { who had pre-marital sex reporting multiple } \\
\text { partnerships }^{2}\end{array}$ & 24.5 & 21.4 \\
\hline $\begin{array}{l}\text { \% young people aged } 15-24 \text { who had pre-marital sex reporting ever use of } \\
\text { condoms }{ }^{2}\end{array}$ & 27.0 & 7.0 \\
\hline $\begin{array}{l}\text { \% young people aged } 15-24 \text { who had pre-marital sex reporting consistent } \\
\text { condom use }\end{array}$ & 12.7 & 2.5 \\
\hline $\begin{array}{l}\% \text { young people aged } 15-24 \text { who had pre-marital sex reporting forced sexual } \\
\text { experience }^{2}\end{array}$ & 3.0 & 18.0 \\
\hline Pregnancy and childbirth & & \\
\hline$\%$ 20-24 year-old young women who had given birth before age $18^{1}$ & & 21.7 \\
\hline$\%$ married young women aged $15-24$ with three or more children ${ }^{1}$ & & 12.9 \\
\hline Neonatal mortality rate among adolescent mothers (per 1,000 live births) ${ }^{1}$ & & 54.2 \\
\hline Unintended pregnancy and abortion & & \\
\hline$\%$ births in the last five years to mothers aged $15-24$ that were unplanned ${ }^{1}$ & & 16.9 \\
\hline$\%$ unmarried abortion-seekers delaying abortion into the second trimester ${ }^{4}$ & & 25.3 \\
\hline$\%$ married abortion-seekers delaying abortion into the second trimester ${ }^{4}$ & & 9.4 \\
\hline Symptoms of genital infection and HIV & & \\
\hline $\begin{array}{l}\% \text { young people aged } 15-14 \text { reporting symptoms of genital infection in the } \\
\text { last three months }{ }^{2}\end{array}$ & 4.5 & 16.8 \\
\hline$\%$ young people aged $15-24$ who are HIV positive ${ }^{3}$ & 0.09 & 0.11 \\
\hline Malnutrition & & \\
\hline$\%$ young people aged $15-24$ who were moderately or severely anaemic ${ }^{3}$ & 11.1 & 17.4 \\
\hline
\end{tabular}

Sources: ${ }^{1}$ International Institute for Population Sciences and Macro International, 2007; ${ }^{2}$ International Institute for Population Sciences and Population Council, 2010; ${ }^{3}$ Parasuraman et al., 2009; ${ }^{4}$ Jejeebhoy et al., 2010. ${ }^{*}$ Cumulative percentages of young people aged 15-24 who experienced first pre-marital sex before age 20, calculated using life table techniques. 
of young women. While the age at marriage for women has undergone a secular increase, the reality is that almost half of all women aged 20-24 were married by 18 years as recently as in 2006 (International Institute for Population Sciences and Macro International, 2007). Indeed, trend data show that the percentage of women marrying by age 18 declined by just seven percentage points between 1992 and 2006 (Ministry of Health and Family Welfare, 2009a). In eight out of 29 states (Andhra Pradesh, Bihar, Chhattisgarh, Jharkhand, Madhya Pradesh, Rajasthan, Uttar Pradesh and West Bengal), moreover, between two-fifths and twothirds of young women were married by 18 years. Further, wide disparities are evident in marriage age: poor, rural and poorly educated young women, and those from scheduled castes (SCs) and scheduled tribes (STs) are considerably more likely than other women to have experienced child marriage. While large proportions of young men were married before they were legally permitted to do so, just 10 percent married before they were 18 (International Institute for Population Sciences and Macro International, 2007).

While marriage marks the onset of sexual activity among the large majority of young women, there is growing evidence of premarital onset of sexual activity in adolescence particularly among young men. Evidence from the Youth Study shows that 11 percent of young men and 5 percent of young women aged 15-24 had engaged in pre-marital sex in adolescence, that is, before age 20 (International Institute for Population Sciences and Population Council, 2010). Differentials are apparent, with rural young women twice as likely (6\% versus $3 \%)$ and rural young men almost three times as likely $(14 \%$ versus $5 \%$ ) to have experienced pre-marital sex in adolescence as their urban counterparts.

\section{Unsafe, unwanted or forced sexual relations}

Where sexual relations take place, they are often unsafe and for many young women, unwanted or forced. For example, the Youth Study reports that among sexually experienced unmarried young men and women, 25 percent and 21 percent, respectively, had engaged in sex with more than one partner (International Institute for Population Sciences and Population Council, 2010). Just 27 percent of young men and 7 percent of young women had ever used a condom, and even fewer, 13 percent and 3 percent, respectively, had used a condom consistently. Moreover, 18 percent of the young women (and 3\% of the young men) had been forced to engage in sex (Santhya, Jejeebhoy and Acharya, 2011a).

Among the married too, the Youth Study shows that just 28 percent of young women aged 15-24 were practising contraception (International Institute for Population Sciences and Population Council, 2010). Fewer than one in five young women were currently practising contraception in seven of the 29 states (Bihar, Chhattisgarh, Jharkhand, Meghalaya, Nagaland, Orissa and Rajasthan) (Parasuraman et al., 2009). Differentials were notable: adolescent girls were only one-third as likely as young women (20-24 year-olds) to currently use contraceptives, and young women from the poorest households only half as likely as those from the richest households to do so.

Married young women were also likely, moreover, to face sexual violence; evidence from the Youth Study indicates that almost one-third (32\%) of married young women had ever experienced sexual violence perpetrated by their husband (International Institute for Population Sciences and Population Council, 2010). Findings, moreover, indicate that sexual violence within marriage is more common in the 
northern states (40-54\%) than in the western state of Maharashtra and the southern states (10-27\%).

\section{Childbearing in childhood}

Consequent to early marriage, childbearing is initiated early and multiple pregnancies characterise the life of many young women. One in five young women aged 20-24 had their first baby before they were 18 , and one in eight young women aged 20-24 had three children (International Institute for Population Sciences and Macro International, 2007). In five of the 29 states (Andhra Pradesh, Bihar, Jharkhand, West Bengal, Arunachal Pradesh), between one-quarter and one-third of young women had their first birth by age 18. Rural young women were twice as likely as urban women to have their first birth by age 18 . Differences by education were striking: 39 percent of young women with no education compared to 1 percent of those with 12 or more years of schooling had their first birth before age 18 . As a result, both maternal and neonatal mortality are higher among the young than among older women: 45 percent of all maternal deaths take place among those aged 15-24 (Office of the Registrar General, India, 2011) and neonatal mortality rates range from 54 per 1,000 live births among those aged $15-19$ to 34 and 38, respectively, among those aged 20-29 and 30-39 (International Institute for Population Sciences and Macro International, 2007). Rural adolescents are particularly at risk with neonatal mortality rates as high as 60 per 1,000 live births (compared to 31 among urban adolescents).

While child bearing among the young takes place largely within a marital relationship, pregnancy is indeed reported among significant minorities of sexually experienced young women. For example, the Youth Study observes that among those who reported engaging in pre-marital sex with a romantic partner, 4 percent of young men and 9 percent of young women reported that they or their partner had experienced a pregnancy (International Institute for Population Sciences and Population Council, 2010). In a study of college students in Gujarat, 17 percent of sexually experienced male students reported that they had made a girl pregnant and 8 percent of sexually experienced female students reported that they had experienced a pregnancy (Sujay, 2009).

\section{Unplanned pregnancy and abortion}

Unplanned fertility is experienced by considerable proportions of young women. As many as 14 percent and 18 percent of births to adolescent mothers and young mothers, respectively, in the five years preceding the National Family Health Survey (NFHS)-3 survey, were unplanned (International Institute for Population Sciences and Macro International, 2007).

While not much is known about abortion among the young, evidence suggests that young women-irrespective of marital status-are more disadvantaged than adult women, and that unmarried young women are particularly disadvantaged. It is estimated that between one and 10 percent of abortion-seekers in India are adolescents (Ganatra, 2000), though a few facility-based studies report that the proportion of adolescent abortion-seekers is as high as one in three (Chhabra et al., 1988; Solapurkar and Sangam, 1985). A community-based study in rural Maharashtra reports that young women aged 15-24 constituted over one-half of married abortion-seekers in the area (Ganatra and Hirve, 2002). In the study of college students in Gujarat cited earlier, most pregnancies were aborted (Sujay, 2009). 
Reproductive Tract Infections (RTIs), Sexually Transmitted Infections (STIs) and HIV

The Youth Study reports that significant proportions of youth had experienced symptoms of genital infection: 5 percent and 17 percent of young men and women, respectively. Reported symptoms of genital infection in the three months preceding the interview, with the married somewhat more likely than the unmarried to so report (International Institute for Population Sciences and Population Council, 2010). Moreover, NFHS data suggest that young women were as likely as adult women to report STIs or symptoms of STIs (International Institute for Population Sciences and Macro International, 2007). As regards HIV prevalence, data indicate that age-specific HIV prevalence rates are similar among young men and young women aged 15-24 (0.09 and 0.11 respectively) (Parasuraman et al., 2009).

\section{Malnutrition}

Malnutrition characterises the life of many young people, particularly young women; 17 percent and 11 percent of young women and men, respectively, were moderately or severely anaemic (Parasuraman et al., 2009). Adolescent girls and young women were equally likely to be anaemic, though adolescent boys were much more likely to be anaemic than young men. Differences by education are notable; for example, among young women, 22 percent of those with no education compared to 13 percent of those who had completed high school were moderately or severely anaemic. 


\section{Policy initiatives to address young people's sexual and reproductive health needs and rights}

The significant shift in the conceptualisation of population and reproductive health issues during the 1990s focused greater attention on the health concerns of young people. At the same time, the growing HIV/AIDS epidemic in India and the recognition of its rapid spread among young people led to a greater openness in addressing issues relating to sex among young people. These shifts are clearly reflected in several policies adopted since the 1990s. Notable among national policies that address young people's sexual and reproductive health needs and rights are the National Population Policy 2000, the National AIDS Prevention and Control Policy 2002 and the National Youth Policy 2003, all of which recognise the need to address young people as a special and vulnerable group. In the areas of education and skill development of young people, the National Policy on Education 1986 (as modified in 1992) and the National Skill Development Policy 2009, likewise, have reiterated the need to equip young people with adequate schooling and skills to compete in a globalising world. Key policies and the Ministries responsible for these policies and for their translation into programmes have been summarised in Appendix 1.

Key policies addressing the sexual and reproductive health and rights of young people

The National Population Policy 2000 recognised, for the first time, that adolescents constitute an underserved group with special sexual and reproductive health needs, and advocates special programmatic attention to addressing this sub-population (Ministry of Health and Family Welfare, 2000). It recommends the need to ensure for adolescents access to sexual and reproductive health information, counselling and services that are affordable and accessible. It also underscores the need to "strengthen primary health centres and sub-centres to provide counselling, both to adolescents and also to newly-weds".

Recognising the special vulnerability of young people, the National AIDS Prevention and Control Policy 2002 notes the need to promote a better understanding of HIV infection and safer sex practices among the young (National AIDS Control Organisation, 2002). The Policy stresses a variety of measures to prevent risky behaviour among young people including awareness building, condom promotion, creation of an enabling environment and reinforcing traditional Indian moral values. It advocates the provision of HIV/AIDS education in schools and colleges through curricular and co-curricular activities, as well as through youth organisations for those outside of educational institutions.

The National Youth Policy 2003 and the more recent draft National Youth Policy 2010 have underscored the multiple needs of the young and the need for holistic and multipronged action. The National Youth Policy addresses the needs of those aged 13-35 but recognises adolescents (aged 13-19) as a special group requiring different 
strategies from those appropriate for young adults (aged 20-35) (Ministry of Youth Affairs and Sports, 2003). With regard to health issues, it acknowledges the vulnerability of young people in the sexual and reproductive health arena, and advocates the provision of free, state-sponsored counselling services for young people, the establishment of "adolescent clinics" to provide appropriate counselling and treatment, and the establishment of Youth Health Associations at the grassroots level to provide family welfare and counselling services.

The draft National Youth Policy 2010 reiterates many of these commitments (The Rajiv Gandhi National Institute of Youth Development, 2010). It argues for an integrated and collaborative approach to development programmes for young people, and for mainstreaming their needs and concerns in overall national development policies. Notably, the draft Youth Policy has redefined the age range of the population to which it refers: 13-30 instead of 13-35. It argues for programming for three age groups of this population-13-18, 19-25 and 26-30 years-recognising that each age group is at a different stage of development and has different needs. A key objective of the policy is to enable healthy sexual transitions among young people: "facilitate access... to basic health facilities and services, promote a healthy lifestyle free of substance abuse and other unhealthy addictions, and dissuade them from engaging in harmful sexual practices." The policy interventions and plan of action articulated in the draft Youth Policy are somewhat bolder and cover more issues than those reflected in other policies. For example, it advocates organising comprehensive thematic campaigns on such issues as HIV/AIDS, substance abuse, sanitation and hygiene, and nutrition; setting up Youth Friendly Information Centres that will provide information, skills and services that enable married and unmarried young people to limit risky behaviours; promoting social marketing of condoms through youth clubs and youth development centres, and establishing linkages for referrals between health services and Voluntary Counselling and Testing Centres (VCTCs), STI services and youth-friendly information services. It also recommends the mobilisation of youth through youth clubs and other community-based organisations to promote healthy lifestyles.

Several other policies also acknowledge the need to pay special attention to the sexual and reproductive health of young people. For example, the National Health Policy 2000 recognises the need to raise awareness among school and college students about health-promoting behaviours (Ministry of Health and Family Welfare, 2002). The National Policy on Education 1986 (as modified in 1992) emphasises that educational programmes should actively motivate and inform young people about family planning and responsible parenthood (Ministry of Human Resource Development, 1998). The National Curriculum Framework 2005 also articulates the need for integrating adolescence education within the school curriculum (National Council of Educational Research and Training, 2005). Further, recognising the special needs of adolescents, the National Plan of Action for Children 2005 argues for actions to enable adolescents up to age 18 to have access to physical and mental health services, and to build awareness of sexual and reproductive health matters (Ministry of Women and Child Development, 2005).

Also notable is the commitment to addressing the needs of young people articulated in the current Five Year Plan, that is, the XI ${ }^{\text {th }}$ Plan (2007-12). The Plan clearly recognises young people as a group with special and distinct needs and underscores the importance of investing in them. It acknowledges, moreover, that despite measures taken in earlier 
Plans, the nation did not meet its $\mathrm{X}^{\text {th }}$ Plan targets for young people (Planning Commission, 2008a; 2008b). In the area of health, the $\mathrm{XI}^{\text {th }}$ Plan aims to give special attention to the health of adolescent girls; it notes that adolescents have been largely neglected and recommends that activities are stepped up and new activities initiated, including counselling for girls and monthly meetings for girls held by Anganwadi Workers (AWWs) and Auxiliary Nurse Midwives (ANMs). It proposes multifaceted areas of focus including: (a) nutrition and health education for adolescents; (b) optimum health and nutrition interventions during pregnancy; (c) orientation and training of health service delivery personnel to build awareness of and provide youth-friendly services to young people seeking reproductive and sexual health services; (d) development of materials for communication and behavioural change; and (e) provision of adolescent-/youth- friendly services at all Primary Health Centres (PHCs) and Community Health Centres (CHCs), including through the establishment of a special window to serve their needs. Recognising, moreover, that many young people experience mental health problems, it identifies the need for budgetary allocation to address such problems, specifically, through the appointment of counsellors in all schools and the provision of helplines equipped to reach out to young people in need.

\section{Key policies promoting empowerment, and gender equity and equality among young people}

Almost all the policies reviewed in this paper have articulated the need for a multi-sectoral focus on promoting empowerment, and gender equity and equality among young people. A range of strategies have been outlined. Notable among these is a commitment to address the issue of early marriage. Various policies, including those pertaining to population, youth and women's empowerment, have advocated special programmatic attention to delay the age at marriage and to enforce the Child Marriage Restraint Act 1978. The XI ${ }^{\text {th }}$ Plan, similarly, stresses advocacy efforts to delay the age at marriage, as well as the need for special attention to strengthen enforcement mechanisms for implementing the Prohibition of Child Marriage Act 2006. It calls for partnerships between government agencies (Ministry of Women and Child Development) and civil society groups, Panchayati Raj Institutions (PRIs), community-based organisations, Self-Help Groups (SHGs) and religious leaders to mobilise communities and develop community initiatives to support delayed marriage. The Plan also emphasises the implementation of compulsory registration of marriages (Planning Commission, 2008a; 2008b).

Several of these policies also emphasise the eradication of extreme forms of gender discrimination, particularly violence against women and girls. The draft Youth Policy 2010 contains a number of recommendations for promoting gender justice and equality—mainstreaming gender concerns and addressing sexual harassment, violence and other acts against young women, for example (The Rajiv Gandhi National Institute of Youth Development, 2010). The National Policy for the Empowerment of Women 2001 also highlights the need to address the vulnerability of girls to gender-based violence (Ministry of Women and Child Development, 2001). The National Plan of Action for Children 2005, similarly, calls for greater attention to protecting young people from violence and abuse (Ministry of Women and Child Development, 2005). The XI ${ }^{\text {th }}$ Plan also focuses on eradicating violence against women and girls. Departing from previous Plans, it views violence as a public health issue and calls for 
the training of medical personnel at all levels of the health care system to recognise and report violence against women and children. It also introduces the Integrated Child Protection Scheme (ICPS) and the Scheme for Relief and Rehabilitation of Victims of Sexual Assault under which Community Vigilance Groups, SHGs and Youth Groups will be entrusted with the task of helping to protect girls from violence. The Helpline for children is also to be expanded into rural areas and all districts of the country, and activities intended to build community awareness and support those who have experienced abuse are to be developed with the assistance of NGOs (Planning Commission, 2008a; 2008b).

Many of these policies also recognise the need for young people to acquire life skills. For example, the National Youth Policy 2003 stresses the importance of life skills building (Ministry of Youth Affairs and Sports, 2003). The draft National Youth Policy 2010, similarly, notes the need for developing education and training materials, and imparting training that combines the provision of information and life skills, thereby enabling young people to adopt protective actions. It also recommends the need to mobilise young people through youth clubs and other community-based organisations to impart training in life skills (The Rajiv Gandhi National Institute of Youth Development, 2010). The XI ${ }^{\text {th }}$ Plan, similarly, emphasises the provision of life skills, young people's empowerment, and greater female participation in development programmes for the young. It also advocates a strengthening and expansion of the youth club movement, including a larger female membership (Planning Commission, 2008a; 2008b).

\section{Key policies addressing the nutritional needs of young people}

Most of the policies discussed above highlight the need to address the issue of nutritional deficiencies in adolescents, particularly girls: the National Population Policy 2000 advocates the provision of food supplements to adolescent girls and nutritional services through the Integrated Child Development Scheme (ICDS) (Ministry Of Health and Family Welfare, 2000); the National Youth Policy 2003, likewise, stresses the need to redress gender imbalances in nutritional status (Ministry of Youth Affairs and Sports, 2003), and the National Policy for the Empowerment of Women 2001 identifies adolescent girls as a vulnerable group and highlights the need to address their nutritional needs (Ministry of Women and Child Development, 2001). So also, the $\mathrm{XI}^{\text {th }}$ Plan emphasises the nutritional needs of adolescents, especially girls, and aims to reduce anaemia among women and girls by 50 percent by the end of the Plan period. It recommends that adolescents (ages 11-18) and school-aged children (ages 6-10) should be covered by the National Nutritional Anaemia Prophylaxis Programme, and that weekly iron and folic acid supplementation is provided to adolescent girls (Planning Commission, 2008a; 2008b).

\section{Key policies addressing young people's education and skill-building needs}

A number of policies mentioned above have also called attention to the need to improve the educational attainment of young people and enhance their acquisition of livelihood skills. The National Youth Policy 2003 reiterates a commitment to enable 
young people to attain high levels of education and access employment opportunities, and to address gender disparity in schooling and economic opportunities (Ministry of Youth Affairs and Sports, 2003). The draft Youth Policy 2010 also argues for the need to enhance educational and economic opportunities for the young. Its recommendations include sensitising parents of school-going girls to ensure that they complete their education, supporting girls who discontinue their education prematurely and changing traditional perceptions of the position of women among the young (The Rajiv Gandhi National Institute of Youth Development, 2010).

The National Policy on Education 1986 (as modified in 1992) highlights the importance of universal school enrolment and completion and stresses the need to reduce gender imbalances in school attendance and completion (Ministry of Human Resource Development, 1998). The very recently enacted Right of Children to Free and Compulsory Education Act 2009, moreover, has, for the first time, made primary education compulsory. Indicating that all children aged 6-14 and studying in Classes I-VIII have the right to obtain free and compulsory education, it stipulates that children aged above 15 who have not completed Class VIII are also eligible for these benefits, and calls upon state governments to ensure the availability of schools that are physically accessible to children, ensure elementary school attendance and completion, and ensure good quality elementary education (Ministry of Human Resource Development, 2011). The National Policy for the Empowerment of Women 2001 also highlights the need to address girls' education (Ministry of Women and Child Development, 2001). The National Plan of Action for Children 2005, similarly, calls for greater attention to young people's education and development opportunities (Ministry of Women and Child Development, 2005).

Of special importance to young people is the proposed National Skill Development Policy. The Policy calls for establishing a National Skills Development Initiative that aims to empower individuals through improved skills, knowledge and qualifications to gain access to employment in an increasingly competitive global market (Ministry of Labour, 2009). It aims to meet, by 2022, the skilling needs of 500 million individuals, with special attention to women, youth and school dropouts by motivating youth to participate in training programmes through activities conducted through village or block skills development centres as well as incentive mechanisms. The Policy further proposes to strengthen the capacity of schools to lay a solid foundation for young people to acquire employable skills and engage in skill upgradation throughout their working life, and use school education as a tool to increase awareness of vocational skillbuilding options; additionally, it proposes to provide alternative education in combination with skill development opportunities to out-of-school youth.

The strategies outlined in the $\mathrm{XI}^{\text {th }}$ Plan mirror these commitments (Planning Commission, 2008b). The $\mathrm{XI}^{\text {th }}$ Plan, similarly, prioritises the need to attain an educated youth population. It aims to raise the minimum level of education to Class $\mathrm{X}$ and universalise access to secondary education. Indeed, it proposes to increase the gross enrolment ratio in secondary education from 52 percent in 2004-05 to 75 percent by 2011-12, and to provide a secondary school within five $\mathrm{km}$ of every habitation (Planning Commission, 2008b). In addition, the Plan focuses on improving the quality, both of curriculum content and teacher skills. For example, Information and Communications Technology (ICT) 
infrastructure is to be established at government and government-aided secondary and senior secondary schools (about 80,000) during the Plan period. Moreover, the Plan recognises adolescent girls as particularly disadvantaged and proposes measures to enhance their school enrolment and continuation.

\section{Key policies addressing the need for} building a supportive environment for young people

The draft Youth Policy 2010 has emphasised the need to build a supportive environment for young people (The Rajiv Gandhi National Institute of Youth Development, 2010). It notes that society, in general, and the family and educational institutions, in particular, must take special responsibility for enabling adolescents to make a healthy transition to adulthood. It advocates engaging parents in awareness-raising programmes implemented in schools and through other platforms, sensitising parents about the special needs and concerns of female children and dissuading them from discriminating against girls, working with families to support girls' schooling, and enlisting the support of community elders and leaders in eliminating such practices as early marriage and dowry. It also calls for organising orientation and training programmes for teachers on value-based education.

\section{Gaps}

As can be noted, a large number of policies formulated at the national level in the recent past have clearly articulated a commitment to meeting the sexual and reproductive health needs of adolescents and youth. However, most policies have overlooked the fact that young people are not a homogenous group. For example, the National Population Policy 2000 has neglected to discuss whether it is advocating services for all adolescents or exclusively for married adolescents. While it does not specifically indicate that unmarried adolescents are ineligible to access services, such statements as "reproductive health services for adolescent girls and boys are especially significant in rural India, where adolescent marriage and pregnancy are widely prevalent", suggest a certain ambivalence with regard to the extent to which services will be made available to meet the sexual and reproductive health needs of the unmarried. On the other hand, the focus of the National AIDS Prevention and Control Policy 2002 is largely on unmarried young people (students in school and college) and to a certain extent, married young men. Even though the Policy advocates reaching out-of-school youth, who obviously include both the unmarried and married, through networks of youth organisations, sports clubs, the National Service Scheme (NSS) and Nehru Yuvak Kendras (NYK), the fact that most of these networks largely cater to young males suggests that unmarried outof-school and married adolescent girls and young women are unlikely to be reached by the proposed programmes.

While the National Youth Policy 2003 remained ambiguous about the extent to which services were to be made available to the unmarried or to girls, the draft Youth Policy 2010 is more specific. However, it too has limitations: on the one hand, it recognises the heterogeneity of young people, and on the other, it fails to recognise gender differences in the situation and needs of young people. Moreover, the three sub-groups of young people described in the Policy (13-18, 19-25 and 26-30 year-olds) obscure many key transitions that youth face. For example, although almost one-half of young women are married before age 18, the plan of action for those aged 13-18 emphasises in-school adolescents, and does not take note of the need for delaying marriage among girls more generally, and supporting those who marry as children. Similarly, the second 
group (ages 19-25) is described as comprising youth who are in the process of "completing their education and getting into a career"; but fails to recognise, in its plan of action, that for the majority of young women in particular, these ages represent a period characterised by transitions to marriage and childbearing.

While almost all policies underscore the need to raise awareness about sexual and reproductive health issues among young people, many do not recognise young people's need for sexual and reproductive health services. For example, the National AIDS Prevention and Control Policy 2002 is notably silent about the delivery of any specially packaged services for young people. Similarly, the National Health Policy 2002 does not contain any reference to young people's need for sexual and reproductive health services or counselling. Further, policies that have recognised such needs are somewhat ambiguous about the nature of services to be made available to young people. For example, the focus of the National Population Policy 2000 and the XI ${ }^{\text {th }}$ FiveYear Plan is clearly on the less controversial aspects of sexual and reproductive health—counselling and dissemination of information-but not quite as clearly on the provision of services to unmarried adolescents. In the National Population Policy, adolescents are included as a target audience for community-level education campaigns about the availability of safe abortion services and the dangers of unsafe abortion, but they are not included as a target group for safe and legal abortion services. Also, while nutritional services (because of their link with subsequent safe pregnancy) and pregnancyrelated care are recommended, other key services are not mentioned. Similarly, the National Youth Policy 2003 leaves ambiguous the kinds of services that the recommended adolescent clinics and programmes will provide and the extent to which services will be available to the unmarried or to girls. Likewise, although the policy interventions and plan of action articulated in the draft Youth Policy 2010 are somewhat bolder and encompass a wider range of actions than do other policies, it shies away from highlighting young people's need for a wide range of sexual and reproductive health services. The emphasis seems to be tilted towards preventing HIV/AIDS and substance abuse; young people's need for such services as contraceptive counselling and supplies, treatment of genital infections, safe abortion services and maternal health services is not at all mentioned.

Overall, most of the national policies reviewed in this paper are committed to addressing the gender disparities underlying the poor sexual and reproductive health situation of young people. However, most policy documents, except the draft Youth Policy 2010, are vague about how these commitments are to be operationalised. Likewise, while most policies indicate the need to create a safe environment for young people, the measures to be taken to do so are rarely described, except, again, in the draft Youth Policy. 


\section{CHAPTER 3}

\section{Laws to address young people's sexual and reproductive health and rights}

There are a number of laws in India that have relevance, directly or indirectly, for young people's sexual and reproductive health and rights. We focus here on five laws that have a bearing on young people's sexual and reproductive health and rights; three of these have been enacted in the last decade.

\section{Prohibition of Child Marriage Act 2006}

The Child Marriage Restraint Act of 1929 and the Child Marriage Restraint Act of 1978 prohibit marriage to a girl before she reaches age 18 and to a boy before he reaches age 21 . In the case of underage marriages, the Act stipulates that the parent or guardian (or the groom if aged above 21) who is responsible for the marriage is punishable with simple imprisonment up to just three months and is liable to a fine. Notwithstanding this Act, even as recently as 2006-07, almost half of all young women aged 20-24 had married before they were 18 (International Institute for Population Sciences and Macro International, 2007).

The more recent Prohibition of Child Marriage Act 2006 has considerably strengthened legislation in the case of child marriage (age 18 and 21 for girls and boys, respectively, as before). It imposes the following: (a) the district court can order both parties to the marriage and their parents to return all money, valuables and gifts received; (b) the family of the groom may be asked to pay maintenance to the bride-to-be until her remarriage; (c) the groom, if over age 18 , is liable for two years imprisonment and/or a fine of up to Rs. 1 lakh; (d) anyone who "performs, conducts, directs or abets" a child marriage will be punishable with rigorous imprisonment for up to two years and a fine of Rs. 1 lakh; (e) anyone who does anything to promote the marriage or permits it to be solemnised or fails to prevent it from being solemnised is also punishable with the same quantum; and (f) each state will appoint a Child Marriage Prohibition Officer whose task is to prevent such marriages from taking place, sensitise communities about early marriage and collect evidence for effective prosecution of those contravening the provisions of the Act (Ministry of Law and Justice, 2007).

\section{Protection of Women from Domestic Violence Act 2005}

Prior to 2006, civil law options available to women experiencing domestic violence did not address the many implications of domestic violence. The Protection of Women from Domestic Violence Act 2005, passed in 2006, goes a long way in strengthening women's options and protection (Ministry of Women and Child Development, 2006a). For one, it adopts a broad definition of domestic violence, including both actual abuse and the threat of abuse: abuse covers physical (beating, pushing), sexual (including being forced into sex or into watching pornography), verbal, emotional and economic (not providing for wife and children) violence; it also covers dowry-related harassment. Also of relevance to young women is that it includes 
being forced not to attend an educational institution, and being prevented from taking a job or leaving the home; it also includes being forced to marry someone against their will or being prevented from marrying someone they wish to marry. Under the Act, the state must appoint a Protection Officer whose task is to support women who experience violence and ensure that the protection order passed by a Magistrate is not breached. The Act offers women considerable protection, including the right to reside in the matrimonial or shared household and the imposition of restraining orders on the perpetrator. In addition, under the Act, NGOs may register with the state as service providers, to support women's needs by way of legal aid, health care, economic support and so on.

The Immoral Traffic (Prevention) Amendment Bill 2006

The Immoral Traffic (Prevention) Amendment Bill 2006 amended the Immoral Traffic (Prevention) Act 1956, to combat trafficking and sexual exploitation for commercial purposes (Ministry of Women and Child Development, 2006b). The Bill specifically covers trafficking for the purposes of prostitution, as well as punishment to those involved in trafficking of persons-usually girls-for this purpose. Key provisions include the deletion of the clause that penalised sex workers for soliciting clients, and more stringent punishment for those committing trafficking as well as the clients of trafficked victims; additionally, it strengthens the role of authorities at central and state levels to address trafficking.

\section{The Protection of Children from Sexual Offences Bill 2011}

The Protection of Children from Sexual Offences Bill 2011, introduced in the Rajya Sabha, seeks to protect children, defined as those aged below 18 years, from sexual assault, sexual harassment and pornography, and provides for the establishment of special courts for the trial of such offences (Ministry of Women and Child Development, 2011). It seeks to prevent the inducement or coercion of a child to engage in any sexual activity, the use of children in prostitution or other sexual practices, and the use of children in pornographic performances and materials. The Bill treats sexual assault as an aggravated offence when a person in authority or position of trust commits the offence. It also contains guidelines for the media to sensitively and discreetly report cases of sexual offence.

\section{Medical Termination of Pregnancy Act (MTP) 1971 and Amendment of 2002}

The MTP Act of 1971 and the 2002 amendments to the Act have ensured women's right to terminate an unwanted pregnancy safely and confidentially (Government of India, 1971). It allows women to seek pregnancy termination in a wide range of circumstances-if the pregnancy has resulted from rape, if the pregnancy has adverse health consequences for the woman, if there is evidence of foetal malformation, or if the pregnancy was the result of contraceptive failure, for example. Pregnancies of up to 20 weeks may be terminated legally; however, the concurrence of at least two physicians is required for pregnancies of more than 12 weeks' gestation. While the Act makes no distinction between the rights of the married and the unmarried, it does require that women under 18 must have parental consent: "No pregnancy of a woman who has not attained the age of 18 years... shall be terminated except with the consent in writing of her guardian”. 


\section{The Right of Children to Free and} Compulsory Education Act 2009

The links of education to health-promoting behaviours are well-established. While progress has been made in ensuring universal enrolment, even as recently as $2006-07,76$ percent and 83 percent of 6-14 year-old girls and boys, respectively, were attending school, and 32 percent and 42 percent, respectively, of those aged 18-24 had completed high school (International Institute for Population Sciences and Macro International, 2007).

The Right of Children to Free and Compulsory Education Act 2009 places responsibility on the state to ensure free and compulsory enrolment, as well as regular attendance and completion of elementary school, particularly among children from disadvantaged groups; the availability of a neighbourhood school, infrastructure, teaching staff and learning equipment; good quality education; appropriate training of teachers; and the integration of children from socially excluded groups into the school system (Ministry of Human Resource Development, 2011). The Act also places responsibility on parents for ensuring that their children are enrolled in an appropriate elementary school and remain in school until they have completed Class VIII. Additionally, the Act stipulates conditions that may well enhance continuation and regular attendance: that schools must ensure that no child will be held back, subjected to physical punishment or mental harassment, and that regular meetings are held with parents to apprise them of their children's progress.

\section{Gaps}

The most obvious challenge is the country's apparent inability to implement laws, the most glaring of which is the Child Marriage Restraint Act. Laws have not always been enforced appropriately. A review of data from the National Crime Records Bureau (NCRB) indicates that very few cases of crimes against children punishable under Special and Local Laws, including the Immoral Traffic Prevention Act 1956 and the Child Marriage Restraint Act 1929, have been registered (National Crime Records Bureau, 2010). For example, crimes under the Child Marriage Restraint Act reported nationally, ranged from 58 cases in 1999 to 104 cases in 2008. Strangely, cases under the newly enacted Prohibition of Child Marriage Act 2006 have been clubbed with other crimes under Special and Local Laws. Similarly, just 89 cases were recorded in 2009 under the Indian Penal Code (IPC) 372 and 373 that deal with buying and selling of girls aged below 18 for sex work.

Lack of awareness among young people and the wider community of the provisions of laws that address young people's sexual and reproductive health constitutes another challenge. For example, awareness of the legal minimum age at marriage is not universal, even among the young: just 59 percent and 70 percent of young women and men, respectively, were aware of the legal minimum age at marriage for females in the country (International Institute for Population Sciences and Population Council, 2010). Young people and adults, similarly, remain poorly informed about their rights under the MTP Act (International Institute for Population Sciences and Population Council, 2010; Jejeebhoy et al., 2011a; 2011b). Likewise, the midterm review of the $\mathrm{XI}^{\text {th }}$ Plan notes that awareness of the Protection of Women from Domestic Violence Act 2005 is limited; the Act has neither been translated into regional languages nor have information, education and communication efforts been undertaken at the community level, among the police, or in courts to create awareness (Planning Commission, 2011). The 
continuing belief among women and men, including young people, that men are justified in beating their wife in certain circumstances underscores the limited awareness of the Protection of Women from Domestic Violence Act (International Institute for Population Sciences and Macro International, 2007; International Institute for Population Sciences and Population Council, 2010).

Concerns have also been raised about limitations in the provisions of several of these acts. For example, with regard to the Prohibition of Child Marriage Act 2006, it has been argued that there is no provision in the law that stops a child bride from living with her husband and protects her from sexual and other forms of abuse. It has been argued further that by not invalidating a child marriage in all circumstances, and by putting the onus of declaring such a marriage void on the child or the guardians, who would have to go through court proceedings for the same, the Act, in fact, lays the foundation for such an abuse. Moreover, the Act does not make the registration of marriages compulsory (Gonsalves, 2007; Law Commission of India, 2008).

Concerns have also been raised about the different definitions of "child" in various laws (Law Commission of India, 2008): for example, the Child Marriage Restraint Act (1929 and 1978) defines a child as a male under 21 and a female under 18; however, according to the Immoral Traffic (Prevention) Act of 1986, a child is an individual below 16 years, and a minor is an individual aged between 16 and 18, while under the Juvenile Justice (Care and Protection of Children) Act 2000, a child is an individual below 18 . 


\section{CHAPTER 4}

\section{Programme initiatives to address young people's sexual and reproductive health needs and rights}

Since the 1990s, several programmes have been initiated in India that have a considerable focus on the sexual and reproductive health needs and rights of young people. This section describes the six broad areas of youth programming: raising young people's awareness about reproductive and sexual health matters, facilitating their access to sexual and reproductive health counselling and services, supplementing nutrition, addressing gender disparity, enabling young people to acquire a basic minimum level of education and marketable skills, and building a supportive environment. Key programmes and the Ministries responsible for their rollout have been summarised in Appendix 1.

\section{Programmes to raise awareness about sexual and reproductive health issues}

A number of programmes have been implemented to raise awareness about sexual and reproductive health matters among young people. While some of these programmes have targeted young people in school, others have focused on those out of school. Again, some programmes have targeted the population more generally, but have acknowledged young people as a group requiring special attention.

\section{For those in-school}

India has had a long history of programmes intended to provide information to school- and college-going youth on sexual and reproductive health matters. Programme content has, however, evolved considerably, from a focus on population and development issues to one on sexual and reproductive health, safe sex and skill-building to ensure health-promoting practices (see Santhya and Jejeebhoy, 2007). This latter focus was underscored in the Adolescence Education Programme (AEP) launched in 2005 by the Ministry of Human Resource Development and the National AIDS Control Organisation. The AEP seeks to empower young people with accurate, age-appropriate and culturally-relevant information, promote healthy attitudes and develop skills to enable them to respond to real-life situations effectively. The programme focuses on young people in Classes IX and XI. During 2005-06, the AEP was implemented in 112,000 schools and some 288,000 teachers were trained (National AIDS Control Organisation, n.d.).

Unfortunately, since 2006, serious reservations have been expressed in India about the sexuality component of the programme, and several states have banned the provision of adolescence education programmes in state-run schools. Indeed, a Committee on Petitions formed to evolve a consensus on the implementation of the AEP, comprising Rajya Sabha members from several political parties, recommended that 'there should be no sex education in schools' (Rajya Sabha Committee on Petitions, 2009). Following the concerns raised, efforts have been made by several stakeholders including civil society organisations, researchers, UN agencies and concerned government 
departments to generate support for implementing a culturally-sensitive, holistic AEP (Jaya, 2010). The National AIDS Control Organisation and the National Council of Educational Research and Training, for example, established an expert committee that reviewed the original curriculum. The committee reiterated the need to continue AEP in Classes IX and XI and provided state education departments greater flexibility to modify the existing programme, if necessary. A revised curriculum was developed by the National AIDS Control Organisation in collaboration with the Ministry of Human Resource Development, comprising a 16-hour programme in four sections: (a) the passage from childhood to adolescence; (b) Adolescent Reproductive and Sexual Health (ARSH); (c) mental health and substance misuse; and (d) life skills and HIV prevention (National AIDS Control Organisation, 2008a; 2008b). The National Council of Educational Research and Training, with support from UNFPA, has further revised the training and resource materials to be used under the AEP (National Council of Educational Research and Training, 2011). The revised curriculum, under such broad headings as the process of growing up, prevention of HIV/AIDS and prevention of substance/drug abuse, covers such themes as understanding changes during adolescence and being comfortable with them, establishing and maintaining positive and responsible relationships, understanding and challenging stereotypes and discrimination, understanding and reporting abuse and violations, and the prevention of HIV/AIDS and substance abuse.

The AEP is implemented through State Councils of Educational Research and Training/ State Boards with the support of State AIDS Control Societies. During 2009-10, the AEP was implemented in 47,000 of over 145,000 high schools and higher secondary schools across the country (National AIDS Control Organisation, 2010). It is also being implemented, with the support of UNFPA, by such national-level agencies as the Central Board of Secondary Education (CBSE), the Navodaya Vidyalaya Samiti, the Kendriya Vidyalaya Sangathan, the National Institute of Open Schooling and the Council of Boards of Secondary Education (Jaya and Yadav, 2010; National Council of Educational Research and Training, 2011). By the end of 2010, with the support of UNFPA, at least two nodal teachers from 3,000 CBSE schools, all the 919 Kendriya Vidyalaya Sangathan schools and all the 583 Navodaya Vidyalaya Samiti schools had received orientation on adolescence education issues.

The National Council of Educational Research and Training has integrated adolescent concerns in such mainstream subjects as Science, Psychology and Social Sciences and acknowledges that the process of integration requires further strengthening. Moreover, a life skills component has been integrated in the secondary curriculum of the National Institute of Open Schooling that enrols some 400,000 students each year. Drawing on the experience of a pilot experiment in which life skills were integrated in 17 lessons across the subjects of Hindi, English, Science, Social Sciences and Home Science, the Institute is currently in the process of integrating life skills in all the lessons pertaining to these five subjects (approximately 130 lessons) for the academic year 2011-12 (Jaya and Yadav, 2010). The AEP is also being implemented by civil society organisations in partnership with state education departments and state AIDS control societies; for example, the Centre for Development and Population Activities has reached some 300,000 students in 1,485 government secondary schools in Jharkhand, and some 87 master trainers and 2,161 nodal teachers from government schools have been trained to 
impart the AEP curriculum (Centre for Development and Population Activities, 2011). The AEP has also been endorsed by the Rashtriya Madhyamik Shiksha Abhiyan (RMSA) (Ministry of Human Resource Development, 2009a).

Other programmes intended to provide information to school- and college-going youth on sexual and reproductive health matters include the School Health Programme launched in 2008 under the National Rural Health Mission (NRHM), Red Ribbon Clubs (RRCs) established under the National AIDS Control Project NACP-II and NACP-III, the University Talk AIDS Programme and the Youth Unite for Victory on AIDS campaign. The School Health Programme comprises interventions to improve in-school adolescents' awareness of health, hygiene and nutrition matters through curricular formats, and of growing up issues and sexual and reproductive health matters through co-curricular approaches (Ministry of Health and Family Welfare, n.d.). The University Talk AIDS Programme, initiated in 1991 to spread awareness of HIV and safe sex among college students, has reached over seven million young people in the country (National AIDS Control Organisation, 2004). Additionally, while the current status is not known, Yuva, a network of seven youth organisations-the Nehru Yuva Kendra Sangathan, the NSS, the Indian Red Cross Society, the National Cadet Corps (NCC), Bharat Scouts and Guides, the Youth Hostels Association of India and the Association of Indian Universities - under the auspices of the Ministry of Youth Affairs and Sports and the National AIDS Control Organisation, is working towards equipping young people with information and life skills for promoting healthy and safe behaviour and practices (National AIDS Control Organisation, n.d.).

\section{For those out-of-school}

Fewer activities have been conducted to raise awareness about sexual and reproductive health matters among out-of-school youth till relatively recently. However, with the spread of HIV/AIDS, a number of programmes have been initiated for outof-school youth. Again, the key programmes emanate from the NACP and the thrust of the Ministry of Health and Family Welfare on young people.

The Village Talk AIDS Programme conducted by the NACP-II is directed to out-of-school youth. The Nehru Yuva Kendra Sangathan, likewise, has undertaken awareness campaigns, including on sexual and reproductive health matters and HIV/AIDS. However, as noted in the strategy and implementation plan document of NACPIII, the reach of these activities remains limited (National AIDS Control Organisation, 2006). Under NACP-III, RRCs have been established in villages to provide youth-oriented counselling, life skills education, recreation activities and guidance in a confidential and enabling environment. The RRCs serve as a complementary and comprehensive prevention intervention to support and reinforce youth initiatives conducted by community volunteers and link workers. Additionally, vulnerable young people in districts characterised by large concentrations of sex workers, injecting drug users or men having sex with men; significant out migration or high HIV prevalence, are to be reached by link workers who are entrusted with the task of implementing behaviour change communication strategies using life-skills based participatory learning processes. Moreover, with support from the Ministry of Women and Child Development, RRCs are to be established for adolescent girls. 
The National Adolescent Reproductive and Sexual Health Strategy also recognises that out-of-school youth have special information needs. It advocates that awareness-raising activities for youth are implemented at least once a month by ANMs, AWWs, Accredited Social Health Activists (ASHAs), youth group coordinators and male health workers. The themes to be covered range from the importance of delaying marriage and first pregnancy to sexual risk-reduction strategies, gender relations and the role of men (Ministry of Health and Family Welfare, 2006a).

The Ministry of Youth Affairs and Sports, with the support of the UNFPA, has formed 3,824 teen clubs in 64 districts in 31 states; these clubs offer a platform for providing young people with opportunities for life skills-focused experiential learning on reproductive and sexual health issues in a gender sensitive matter, imparting information on education and skills building for better employability, and improving access to youth-friendly and gendersensitive services in the public and private sectors (Ministry of Youth Affairs and Sports, 2011; Narayan and Jaya, 2011).

\section{Gaps}

From this overview, it is evident that various approaches have been adopted to raise awareness about sexual and reproductive health among young people, and that programmes have been implemented for several sub-populations. While these initiatives have been commendable, their implementation has been marred by several obstacles.

First, as evident from the description of these programmes, they have focused more on young people in schools and colleges than those outside the educational system. School-based programmes, moreover, have focused on those in Classes IX and XI. Given the trends in school discontinuation at high school and higher secondary school levels, that is, higher levels of discontinuation among girls than boys, among those belonging to poorer households than richer households and among those belonging to socially excluded groups than others (International Institute for Population Sciences and Population Council, 2010; Ministry of Human Resource Development, 2008a), the most vulnerable young people are less likely than others to be reached by school-based programmes. For example, further analyses of the Youth Study data indicate that youth from economically poor households were less likely than those from wealthier households (3\% of those from the poorest quintile versus $24 \%$ of those from the wealthiest quintile) and those belonging to scheduled castes and tribes were less likely than those belonging to general castes (10-11\% versus $19 \%$ of those belonging to general castes) to have received family life or sex education from schools or colleges (International Institute for Population Sciences and Population Council, 2010). Further, programmes imparted through the NYKS and youth clubs, likewise, are likely to reach more males than females, given the gendered nature of youth participation in government and communityled programmes. The Youth Study also observed that access to information through television programmes, telephone helplines and, to a lesser extent, radio programmes is likely to be limited among young women, particularly the married, whose exposure to the mass media is more limited than that of their male counterparts.

Second, programmes, notably the AEP, have been unevenly implemented and their reach remains limited. The political backlash against the programme has further confounded its implementation. Consequently, as of September 2009, the National AIDS Control 
Organisation-supported AEP remained suspended in eight states, including many that were leading in the implementation of such programmes before the backlash, namely, Madhya Pradesh, Maharashtra, Kerala, Karnataka, Gujarat and Rajasthan. Moreover, just 20 percent of the budgetary allocation in 2009-10 has been utilised (National AIDS Control Organisation, 2009). During 2009-10, the AEP was implemented in only 47,000 of over 145,000 high schools and higher secondary schools across the country (National AIDS Control Organisation, 2010). The implementation of awareness-raising programmes under the National Adolescent Reproductive and Sexual Health Strategy has also been poor; the 6th Joint Review Mission of the $\mathrm{RCH}$ Programme II observes that the majority of the states did not make concerted behaviour change communication efforts towards enhancing knowledge among young people (Ministry of Health and Family Welfare, 2009b). Evidence from the Youth Study reaffirms the limited reach of awareness-raising programmes in the country: just 15 percent of youth had ever received family life or sex education in school or through special programmes sponsored by the government or NGOs. Even among those who had completed high school, only 26 percent and 35 percent of young men and women, respectively, had received such education (International Institute for Population Sciences and Population Council, 2010).

Third, although the AEP has recently made significant efforts to make the content and approach of the programme holistic, a number of concerns remain. For example, although many references are made to sexual relations, what these entail is never discussed or is discussed in vague terms, such as the "student is taught that....sex should be based on consent and respect...." or that sex is "when male and female sex cells unite during intimate physical relationships between two people." Likewise, discussion of contraception is extremely limited.
Methods are explained in abstract and technical terms without indicating their pros and cons, how they are used or their usefulness in preventing disease. Misconceptions, such as the belief that marriage ensures safety from infection or that one cannot become pregnant at first sex, are generally not addressed. Moreover, curricula of programmes for the out-of-school are not readily available, except in the NGO sector, and it is difficult to ascertain the messages conveyed in these programmes.

Fourth, concerns remain with regard to the quality of training imparted to the trainers. Findings from the Youth Study show that although youth gave a generally positive assessment of the education they had received, one-fifth of young men and almost two-fifths of young women reported feeling uncomfortable or embarrassed while receiving family life or sex education, raising questions about the extent to which they were indeed able to participate freely and clarify doubts (International Institute for Population Sciences and Population Council, 2010).

Finally, monitoring and evaluation of these programmes remain weak. It is unclear, for example, how many schools in each state have implemented the programme, how many teachers have been trained or how many students have been exposed to the programme. Also lacking is information on the quality and effectiveness of the programme in enhancing young people's awareness and skills. Without such information, it is difficult to assess the reach or effectiveness of the programme or the kind of support required in terms of teacher training or material provision.

\section{Programmes that facilitate access to sexual and reproductive health counselling and services}

Although policies and programmes in India have underscored the right of young people to sexual and 
reproductive health counselling and services, service delivery has not been youth-friendly or responsive to their unique needs. Compared to awarenessraising programmes, sexual and reproductive health counselling and services are provided overwhelmingly through the National Adolescent Reproductive and Sexual Health Strategy outlined in the $\mathrm{RCH}$ Programme; AIDS control programmes play a smaller role in providing services that are directed to young people.

The Adolescent Reproductive and Sexual Health (ARSH) Strategy focuses on reorganising and strengthening the existing public health system to meet young people's needs, mobilising communities to create an enabling environment and encourage young people to access services, and providing preventive, promotive, curative and referral services to young people (Ministry of Health and Family Welfare, 2006a). It notes that "friendly services are to be made available for all adolescents, married and unmarried, girls and boys". The ARSH programme advocates care at two levels for young people: routine sub-centre clinics run by female health workers and weekly two-hour teen clinics organised at the $\mathrm{PHC} / \mathrm{CHC} /$ district level run by the health worker and medical officer. At the subcentre level, the health worker will provide nonterminal contraceptive methods, routine antenatal care services, abortion-related referrals, RTI/STI/ HIV-related education, nutritional counselling, information on menstrual hygiene, and immunisation of pregnant adolescents. The teen clinics will offer such services as contraceptive supplies, management of menstrual disorders, RTI/STI preventive education and management, pregnancy termination and related counselling, nutritional counselling and counselling for sexual problems.

Also proposed in the National Adolescent Reproductive and Sexual Health Strategy are initiatives to orient medical officers, ANMs and Lady Health Visitors (LHVs) in the provision of sexual and reproductive health services. Orientation programmes underscore the need to address both the married and the unmarried, as well as adolescent girls and boys. They also highlight the significant obstacles that young people may face in seeking information and counselling, including young married women's lack of autonomy, perceptions of poor quality of care and judgemental services at health centres, and young people's own reluctance to discuss sexual matters (Ministry of Health and Family Welfare, 2006b; 2006c).

Other schemes under the NRHM that have relevance for young people include the ASHA scheme, the Janani Suraksha Yojana (JSY) and the School Health Programme. One of the themes included in the training package for ASHAs is adolescent health, orienting ASHAs about pregnancy risks that very young mothers may experience and the vulnerability of adolescent girls to HIV/AIDS, among others (Ministry of Health and Family Welfare, 2006d). A more recently-prepared module on skills that save lives, not yet rolled out, also touches upon adolescent sexual and reproductive health (Ministry of Health and Family Welfare, 2010). The JSY, launched in 2005, provides cash assistance to women who undergo institutional deliveries (Ministry of Health and Family Welfare, 2006e). With revisions in its eligibility criteria in October 2006, all pregnant women in lowperforming states-irrespective of age, parity and economic status - who undergo institutional delivery in a government health facility or an accredited private facility are entitled to receive JSY benefits. The School Health programme, launched in 26 states in 2008, offers a range of screening and referral services to school-going adolescents. For example, anaemia screening and height and weight monitoring activities are incorporated in 
the programme. Additionally, medical officers from PHCs are expected to conduct health check-ups once in six months in schools, and inform adolescents about the services and their location (Ministry of Health and Family Welfare, n.d.).

Several states have begun innovative programmes to address the multifaceted needs of adolescents. In Assam, an ongoing adolescent anaemia initiative in three districts, is expected to benefit 67,000 girls approximately, while in an additional district, an outreach health programme for adolescents is being piloted with support from Mother NGOs (MNGOs) and field-level NGOs. In Punjab, the state has planned to socially market sanitary napkins for school-going adolescent girls as also to operationalise adolescent-friendly health centres in selected districts. In Rajasthan, a sanitary napkins social marketing pilot project is being initiated in selected blocks of four districts. Further, the state has also initiated counselling sessions for adolescent girls through ASHA sahayoginis (Ministry of Health and Family Welfare, 2009b).

Key activities for youth envisaged under NACPIII include the establishment of youth-friendly linkages for referrals and follow-ups between health services and infection-related services, and the promotion of social marketing of condoms through RRCs. Condom promotion efforts are to be undertaken by various youth groups including the Nehru Yuva Kendra Sangathan, and NSS and NCC units (National AIDS Control Organisation, 2006).

\section{Gaps}

Although there are a host of policies and programmes that seek to improve young people's access to sexual and reproductive health services, the implementation of these programmes remains uneven and far from satisfactory, and many young people lack access, in practice, to such services.
As with awareness-raising programmes, the implementation of programmes intended to improve young people's access to sexual and reproductive health services remains uneven. For example, the 6th Joint Review Mission of the RCH Programme II notes that while the majority of the states have reported some progress in the number of functional adolescent health clinics, most of these are located in a few states, namely, Gujarat, Maharashtra, Madhya Pradesh, Himachal Pradesh, Kerala and Punjab (Ministry of Health and Family Welfare, 2009b). Moreover, the few evaluations available suggest that the programme has neither improved access to services among youth nor the quality of services they receive. Evidence from an evaluation of $21 \mathrm{ARSH}$ clinics/centres in Gujarat observes that 17 were functional at the time of the study; of these, ARSH services were provided through OPD hours and days specifically designated for adolescents in just 7 centres and through general OPDs and Integrated Counselling and Testing Centres in the remaining 10 . Moreover, only 10 of the 17 provided auditory and visual privacy. Few young people were aware of the clinics: in just two of 28 focus group discussions with adolescent girls and boys did adolescents report such awareness. Both youth and providers noted that the use of services by young people was limited. Reasons given included lack of privacy, fear of attending clinics located in health centres and hospitals and fears of provider attitudes (Centre for Operations Research and Training, 2009). Evaluations of such programmes as the JSY and the ASHA also indicate their limited reach among young people. For example, evaluations of the JSY indicate that women who had delivered at young ages (less than 18 years) were less likely than others to have availed of the benefits (Lim et al., 2010; Santhya et al., 2011b); those under 18 who deliver at home- the most vulnerable-are not eligible to receive JSY benefits. Likewise, evidence from a recent study of some 150 ASHAs in two districts 
of Rajasthan indicates that their interactions with adolescent and young women remain limited; just one-third of ASHAs reported that they had counselled newly-married women about contraception, for example (Santhya et al., 2011c).

Indirect evidence on the limited reach of programmes intended to facilitate young people's access to sexual and reproductive health services comes from surveys that shed light on young people's health-seeking behaviours. For example, evidence from the Youth Study shows that few sexually experienced unmarried youth had used condoms consistently in pre-marital relationships $(13 \%$ and $3 \%$ of young men and women, respectively) (International Institute for Population Sciences and Population Council, 2010). The NFHS-3 reports that the unmet need for contraception is higher among married young women than adult women (23\% compared to $11 \%$ among those aged $30-34$ ) (International Institute for Population Sciences and Macro International, 2007). District-level studies in Maharashtra and Rajasthan report that adolescents are more likely than older women, and unmarried adolescents are more likely than their married counterparts, to seek abortion from unqualified or untrained providers, and to undergo delayed and second trimester abortions (Jejeebhoy et al., 2010). Data from NFHS-3, likewise, show that maternal health care-seeking is also limited among young women despite the fact that many of them were experiencing their first and most risky pregnancy at a young age. Just 54 percent of young women received three or more antenatal check-ups, 49 percent of the deliveries of young women were attended by a skilled attendant and 37 percent of young women received a postpartum check-up within two days of delivery (Parasuraman et al., 2009). For symptoms of infection too, there is evidence that just 56 percent of young men and 40 percent of young women who experienced symptoms of infection had sought care, and just 4 percent and 11 percent of young men and women, respectively, had ever undergone an HIV test (International Institute for Population Sciences and Population Council, 2010). Also reiterating young people's limited access to sexual and reproductive health services are findings from the Youth Study that a large proportion of youth-two-fifths of young men and one-half of young women-felt uncomfortable to approach health care providers for sexual and reproductive health services, including contraceptive supplies (International Institute for Population Sciences and Population Council, 2010).

Notwithstanding the efforts taken up under the National Adolescent Reproductive and Sexual Health Strategy to sensitise various categories of health care providers to the needs of adolescents, the limited evidence available, raises questions about the quality and content of training. The 6th Joint Review Mission of the RCH Programme II notes that the majority of the states has organised training workshops for various levels of providers on ARSH; but not all medical officers, staff nurses, ANMs, ASHAs and other personnel have been trained (Ministry of Health and Family Welfare, 2009b). The evaluations of ARSH clinics in Gujarat and Maharashtra also raise questions about the quality of provider training and the need for reorientation (Centre for Operations Research and Training, 2009; Indian Institute of Health Management Research, 2010). It is not clear, moreover, whether providers have been adequately oriented to issues relating to the delivery of the expanded services, notably contraceptive services to the unmarried or the limited mobility and decision-making authority of newly-married young women. In fact, evidence currently available, suggests the contrary; for example, although young women's isolation is 
widely known, evidence from NFHS-3 shows that outreach services rarely reach them; thus, while just 11 percent of young women had received a visit at home from a health worker in the three months preceding the survey, adolescent girls were only half as likely as young women (7\% versus 15\%), and unmarried young women were only one-quarter as likely as married young women ( $4 \%$ versus $17 \%$ ) to so report (International Institute for Population Sciences and Macro International, 2007).

While the orientation guides for providers suggest that adolescent-friendly services must be nonthreatening, non-judgemental and understanding of young clients, they do little to change provider attitudes to sexual activity and experience of symptoms of infection among the unmarried (Ministry of Health and Family Welfare, 2006b; 2006c). For example, evidence from a small-scale study in Andhra Pradesh and Madhya Pradesh indicates that a major factor hindering the ability of health care providers to provide sexual and reproductive health services to young people is their discomfort in doing so. While most stakeholders were comfortable discussing sexual and reproductive health matters with married young women, sizeable proportions reported discomfort in addressing young men and even unmarried young women. Male providers were less uncomfortable providing information and services to young women than were female providers about providing such services to young men (Santhya, Jejeebhoy and Ghosh, 2007). Evidence from the Youth Study reaffirms the limited reach of health care providers; just 3-7 percent of young people had obtained information on sexual matters from a health care provider (International Institute for Population Sciences and Population Council, 2010). Provider attitudes may also have influenced the skewed method mix adopted by married young women. Indeed, despite their young age, almost two in five young women in India were already sterilised, one-quarter were using traditional methods, and just two in five were using modern non-terminal methods most suited to the young. Indeed, the NFHS-3 also found that only one-quarter of women seeking contraception were provided information on the range of methods appropriate for them (International Institute for Population Sciences and Macro International, 2007).

Further, while the particular situation and needs of adolescent boys is recognised, the programmes do not describe the ways in which this situation and these needs will be incorporated into reproductive and child health services. There has been, effectively, a bifurcation of services for men and women, with HIV/AIDS-related activities focused on men, and sexual and reproductive health services focused on women. The ASHA programme and other peripherylevel services overwhelmingly cater to women. Efforts to make men welcome during their wife's antenatal check-ups or at the time of delivery are rare, in general. For example, adolescent fathers (that is, those aged less than 20 at the time of the birth of their youngest child) were less likely than older men to have been informed by a health care worker about such specific signs of pregnancy complications as vaginal bleeding, convulsions and prolonged labour or about what to do in case of a complication (International Institute for Population Sciences and Macro International, 2007). Family planning services are also more focused on women than men, and couple counselling is rarely reported.

In short, while impressive steps have been taken to meet the service needs of young people, the reach of these efforts remains limited. Although the $\mathrm{RCH}$ Programme II has brought married and unmarried young men within its purview, it continues, in reality, to be a largely female-centred programme. Moreover, it has continued, in reality, to exclude 
unmarried young women and has made no special effort to provide reproductive health counselling and services to married young women, especially the newly-married; indeed it has tended to neglect married adolescent girls and young women until they have proven their fertility. At the same time, HIV-related programmes, while technically available to all, have not made any special effort to address the service delivery needs of different groups of young people.

\section{Programmes that address gender disparities and adolescent rights}

Almost every policy has articulated a commitment to reduce gender disparities among young people. Correspondingly, programmes have advocated a range of measures to reduce gender imbalances among young people. The major programmes intended to address gender disparities are the ones supported by the Ministry of Women and Child Development, the Ministry of Youth Affairs and Sports, and the Ministry of Human Resource Development.

Notable among the programmes designed to enhance the status of young women and address gender disparities are the Rajiv Gandhi Scheme for Empowerment of Adolescent Girls (SABLA scheme) introduced in 2010 (Ministry of Women and Child Development, 2010a) and the Kishori Shakti Yojana (KSY, formerly the Adolescent Girls Scheme) initiated in 2000-01 and implemented through the ICDS structure. The SABLA scheme, introduced in 200 districts spread across the country, merges two existing programmes, namely, the KSY and the Nutrition Programme for Adolescent Girls and replaces them. The scheme focuses on both empowering adolescent girls aged 11-18 years and providing them nutritional supplementation; it offers a package of interventions including literacy and numeracy skills training, life skills education, vocational skills training, guidance on public resources, health check-ups and referral services integrated with nutritional supplementation. Implemented through existing Anganwadi centres, the scheme calls for the formation of kishori samooh (girls' groups) in which out-of-school adolescents will meet frequently (two hours a day, three days a week) and in-school girls will meet 1-2 times monthly; it also includes training camps, hands-on learning and sharing of experiences. Although the SABLA scheme, like the KSY, is implemented through existing Anganwadi centres, it is better-funded: a total of Rs. 1,000 crores was allocated to this programme in the Union Budget of 2010-11, which amounts to Rs. 3.8 lakh per annum per Anganwadi centre. The KSY will continue as before in districts in which the SABLA scheme is not implemented.

The National Programme for Youth and Adolescent Development (NPYAD) implemented by the Ministry of Youth Affairs and Sports is another notable scheme that pays special attention to providing opportunities for the holistic development of youth (Ministry of Youth Affairs and Sports, n.d.). A major focus of the scheme is on the empowerment of adolescents through life skills education, counselling, career guidance, and the implementation of residential camps that provide a second chance to acquire basic education and life skills to those left behind in the formal system. The scheme operates through NGOs and NYKS. Life skills education camps are held for batches of 40 young people for a one-week period.

Several cash transfer schemes have been proposed or implemented that focus on improving the status of girls (see, for a detailed review, Sekher, 2010). A programme with national coverage is the Balika Samridhi Yojana, an investment scheme launched in 1997 to improve the status of the girl child by providing monetary incentives for completing 
schooling and postponing marriage till the age of 18. ${ }^{1}$ Yet another scheme introduced on a pilot basis in 2008 is the Dhanalakshmi Conditional Cash Transfer for Girl Child with Insurance Cover scheme (Ministry of Women and Child Development, 2010b). Under this scheme, cash transfers are made to the family of the girl child (preferably the mother) on fulfilling certain specific conditionalities related to birth and registration, immunisation, school enrolment and retention up to Class VIII, and delaying the marriage of the girl child till the age of 18 or later. This scheme is being implemented in eleven blocks across seven States (Andhra Pradesh, Bihar, Chhattisgarh, Jharkhand, Orissa, Punjab and Uttar Pradesh) in the country. The scheme is included in the $\mathrm{XI}^{\text {th }}$ Five Year Plan and an outlay of Rs. 10 crores was provided in the Annual Plan 2009-10. Several state governments have introduced state-specific conditional cash transfer programmes to encourage schooling for girls, delay their marriage and change family and community attitudes towards girls; some examples are the Apni Beti Apna Dhan scheme in Haryana, ${ }^{2}$ the Girl Child Protection Schemes in Andhra Pradesh ${ }^{3}$ and Tamil Nadu, ${ }^{4}$ and the Kanya Jagriti Jyoti scheme in Punjab 5 (Sekher, 2010). Programmes are also implemented by the Department of Education to address gender disparity in educational attainment, for example, the Kasturba Gandhi Balika Vidyalaya (KGBV), Mahila Samakhya, the National Programme for Education of Girls at the Elementary Level (NPEGEL), and the National Scheme of Incentive to Girls for Secondary Education. Mahila Samakhya, launched in the late 1980 s and funded by the central government but implemented only in 83 districts in nine states, aims to educate and empower poor adolescent girls and build life skills among them; it is implemented through kishori sanghas (girls' groups) in over 16,000 villages in nine states (Andhra Pradesh, Assam, Bihar, Gujarat, Jharkhand, Karnataka, Kerala, Uttar Pradesh and Uttarakhand). Under this project, adolescent girls are given non-formal education in the form of functional literacy, leadership and life skills training through Mahila Shikshana Kendras (Ministry of Human Resource Development, 2008b). The NPEGEL has been implemented, as of July 2009, in 423 districts, reached out to 24.4 million girls and trained 0.2 million teachers on gender issues (Ministry of Human Resource Development, 2009b). The life skills approach of the AEP, similarly, focuses on gender equity, changing traditional norms of masculinity and femininity, and empowering

\footnotetext{
${ }^{1}$ Under the scheme, the central government deposits Rs. 500 in a bank/post office in the name of the girl child, which is withdrawn to pay the insurance premium and incremental graded scholarships to the girl child as she graduates from different grades.

${ }^{2}$ Under the scheme, the Haryana government provides a total financial package of Rs. 3,000 to the family on the birth of a girl child (Rs. 500 to the mother of the girl child in cash within 15 days of the birth of the girl child and Rs. 2,500 invested for the girl child for 18 years, provided she remains unmarried till then).

3 The scheme provides a fixed deposit of Rs. 5,000 in the name of the girl child on the condition that she does not marry till the age of 18 and continues her studies up to this age. From high school onwards, the girl student receives Rs. 1,000 a year and then Rs. 20,000 at marriage.

${ }^{4}$ The Tamil Nadu government deposits Rs. 22,200 in the name of the girl child born in families with only one girl child and no other children, and if either of the parents has undergone sterilisation. The interest accrued from the deposit is used to provide a monthly payment of a minimum of Rs. 150 throughout the period of the child's school education, from Class I to Class X; the terminal benefit from the deposit with accrued interest will be given to the girl at the end of 20 years. For families with two girl children and no male child, the government deposits Rs. 15,200.

5 The Punjab government invests Rs. 5,000 for each girl child with the Life Insurance Corporation of India. Previously, only one girl child was eligible; recently, the government has decided to extend the benefit of the scheme to scheduled caste families with two girl children.
} 
adolescent girls in secondary and higher secondary schools (National Council of Educational Research and Training, 2011).

A number of programmes have noted the need to shift from a development-only agenda to a development-plus-rights agenda for adolescents. For example, the ICPS, introduced in 2009-10, seeks to improve the wellbeing of children in difficult circumstances as well as to reduce vulnerable situations and actions that lead to abuse, neglect, exploitation, abandonment and separation of children (Press Information Bureau, 2010). The scheme seeks to achieve these objectives by improving access to and the quality of child protection services, raising public awareness about the situation of children, as well as child rights and protection in India; articulating responsibilities clearly, enforcing accountability for child protection, and establishing structures at all government levels for the delivery of statutory and support services to children. Moreover, the National Commission for the Protection of Child Rights was set up in 2007 to monitor the implementation of child rights in the country (National Commission for the Protection of Child Rights, n.d.). Schemes have also been established for girls and women in difficult circumstances. For example, the Swadhar scheme provides for shelter, food, clothing, counselling, rehabilitation and legal assistance for those in need (Ministry of Women and Child Development, 2002), while the Ujjawala scheme seeks to prevent the trafficking of women and children for commercial sexual exploitation as well as to rescue and rehabilitate victims of trafficking (Ministry of Women and Child Development, 2007).

\section{Gaps}

Although there have been several schemes to address gender imbalances, few have been systematically evaluated to assess their impact on reducing gender disparities or making gender role attitudes more egalitarian. An early evaluation of the Adolescent Girls Scheme, the predecessor of the current KSY, reported that its coverage was too limited to have resulted in any significant change (Lal and Paul, 2003). The evaluation also indicated that the programme should focus more explicitly on the information needs of adolescents in vital areas of reproductive health, behaviour change and the adoption of healthy life styles, as well as the provision of vocational skills. Data on funds allocated and utilised under the KSY, moreover, showed that only four-fifths of the funds allocated have been utilised in 2008-09, and the utilisation was as low as 40-63 percent in states such as Karnataka, Mizoram, Rajasthan, Sikkim and Uttaranchal (Ministry of Women and Child Development, 2010c).

A review of conditional cash transfer schemes that target the girl child notes that the multiplicity of eligibility criteria and conditionalities, the cumbersome procedure for registering under the scheme, lack of coordination across sectors, lack of clarity about the guidelines for implementation and limited involvement of PRIs tend to limit the usefulness of these schemes (Sekher, 2010). Moreover, as the mid-term assessment of the $\mathrm{XI}^{\text {th }}$ Plan reports, there has been little visible change in the living realities of women and children. Further, it observes that the reach of many of these schemes has been limited. For example, during the first three years of the Plan, only 31 percent of the funds allocated for the Dhanalakshmi scheme had been utilised and the scheme has not received any response yet from bigger states like Bihar and Uttar Pradesh (Planning Commission, 2011).

With regard to programmes implemented by the Department of Education to address gender 
disparity in educational attainment, evaluations underscore the need for ensuring the quality of programmes and accelerating efforts to bring in gender sensitivity. For example, the first Joint Review Mission of Mahila Samakhya observes that while all states provide opportunities for girls from marginalised communities to return to schooling in the form of Mahila Shikshana Kendras which are residential, accelerated learning programmes, the training approach and materials need to be reviewed to ensure quality and the learning levels of girls at various exit points need to be assessed. Further, with respect to KGBVs run by Mahila Samakhya, the review mission notes that regular teacher training for KGBV teachers on gender and social issues as well as pedagogy and content requires strengthening across all states. Similarly, with regard to the implementation of NPEGEL by Mahila Samakhya, the mission observes that while in states like Bihar and Assam, the programme has been effective and has taken up remedial teaching, leadership training and vocational training, in states like Gujarat and Andhra Pradesh, the programme needs to be strengthened. Much more impetus is needed to make formal schools gender sensitive (Ministry of Human Resource Development, 2008b).

An evaluation of NPEGEL, likewise, observes that in most of the states visited, implementers have a limited understanding of the objectives and strategies envisaged in the scheme (Ministry of Human Resource Development, 2008c). In most states, activities taken up under the scheme are limited to the Model Cluster School (MCS) and have not percolated to the other schools in the cluster. Cluster-level planning for universal enrolment and attendance of girls and planning for dropouts was not clear in the majority of the clusters. Moreover, state- and district-level officials in many states do not have an understanding of gender issues despite the fact that they have undergone some kind of gender training organised by the Sarva Shiksha Abhiyan (SSA) state offices. The ad-hoc approach to vocational training was evident, perhaps because of limited vision, in almost all the MCS schools visited. The focus was on gender stereotypical craft work and tailoring, embroidery and weaving skills rather than market-driven vocational skills. These classes were being run on a short-term basis without envisaging a time-bound course that would fully equip girls with the skill in which they received training. Gender sensitisation of officials at different levels has not been done and, as a result, the scheme is being viewed as a routine SSA component for building school infrastructure and providing incentives to girls (for example, uniforms, cycles, bags and so on). Similarly, an evaluation of the KGBV scheme reports that the scheme has been well received by parents and the community; has been able to reach out to SC, ST, Other Backward Classes and Muslim girls in very backward and remote regions of the country and has the potential to respond to the educational needs of out-of-school adolescent girls. The evaluation, however, observes that six of the 12 states visited have not adhered to the schematic requirement of reaching out to out-ofschool girls, that a systematic approach to impart the enriched curriculum was not adopted in the KGBVs visited, that no attention is being paid to the issues of adolescence, and that the training given to teachers to enable them to understand and appreciate the special learning needs of the students was woefully inadequate (Ministry of Human Resource Development, 2008c).

Finally, although there have been attempts to incorporate gender sensitisation and rights messages into awareness-building initiatives, including the AEP, the KSY/SABLA programme, the University Talk AIDS programme and other life skills education 
programmes, the extent to which these messages are disseminated and the ways in which they are disseminated are not clear. While orientation guides for various levels of providers do attempt to raise awareness among providers that parents and other gatekeepers may not treat girls and boys equally, training manuals do not stress gender imbalances and their health consequences, or young people's sexual and reproductive rights (Ministry of Health and Family Welfare, 2006b; 2006c). Likewise, notwithstanding the recommendation of the $\mathrm{RCH}$ Programme II National Programme Implementation Plan that gender issues, roles and rights are incorporated into communication packages for adolescents (Ministry of Health and Family Welfare, 2005), attention to gender issues remains limited.

The 6th Joint Review Mission has further noted that there continues to be a lack of privacy in most facilities, including in labour rooms and toilets, and that many facilities treating STIs do not employ counsellors or mechanisms that enable partner notification (Ministry of Health and Family Welfare, 2009b). These constraints tend to affect adolescent girls and young women more than adult women.

\section{Programmes that enhance nutrition among adolescent girls}

Recognising the need of adolescent girls for nutritional supplementation, the National Programme for Adolescent Girls was initiated on a pilot basis, in 2002, in two poorly developed districts of each of the major states and one such district in the remaining states (Nutrition Foundation of India, 2006; Ministry of Women and Child Development, 2010d). Under this programme, adolescent girls are identified and weighed by AWWs once in a quarter, and all those weighing less than $35 \mathrm{~kg}$ are provided six $\mathrm{kg}$ of food grains per month free of cost for three months; besides, the girls and their families are provided nutrition education. The programme has been through many changes in terms of coverage, and since 2005-06, has been functioning in just 51 districts.

The SABLA programme discussed above provides nutritional supplementation to girls in the form of either cooked meals, if feasible, or take-home rations of at least 600 calories and 18-20 grams of proteins for 300 days of the year. At the same time, in conjunction with the NRHM programme, it provides iron and folic acid tablets provided to adults, to adolescent girls as well (Ministry of Women and Child Development, 2010a).

\section{Gaps}

Several gaps have been noted in these programmes. For one, the nutrition programme for adolescent girls has not been consistently implemented. Indeed, over the decade of the 2000s, it was withdrawn for one year, and was implemented only on a pilot basis in selected districts; moreover, with its assimilation into the SABLA programme, it has undergone a further change in 2010 in some districts. These multiple changes make it difficult to assess the reach and effect of the nutritional programme. At the same time, an evaluation of the programme suggests that although AWWs were skilled at identifying malnourished girls, the supply of food grains was erratic; as a result, fewer than 10 percent of adolescent girls crossed the cut-off point of 35 $\mathrm{kg}$, and significant proportions of girls aged 15-19 weighed less than $35 \mathrm{~kg}$ (10-30\% across different states) (Nutrition Foundation of India, 2006). Moreover, data on funds allocated and utilised under the Nutrition Programme for Adolescent Girls show that only one-quarter of the funds allocated have been utilised in 2008-09 (Ministry of Women and Child Development, 2010d). 
Programmes that enable young people to attain a basic minimum level of education and attain marketable skills

The need to enable young people to attain appropriate educational levels and acquire marketable skills to compete in a globalising world is increasingly recognised. Correspondingly, several programmes have been initiated in recent years to promote universal school enrolment and completion. Notable among these is the SSA, intended to universalise elementary education and to provide useful and relevant education to all children in the age group of 6-14 years by 2010 . Recognising that eight years of education are insufficient to prepare adolescents for a globalised world, efforts are underway, through the RMSA, to universalise access to and improve the quality of secondary education (Classes IX-XII); plans are underway to provide secondary (Classes IX-X) and higher secondary schools (Classes XI-XII) within 5 and 7-10 kilometres, respectively, of any habitation; ensure universal access to secondary education by 2017 and universal retention by 2020; and make special efforts to ensure that disadvantaged groups, including girls, are not deprived of this education (Ministry of Human Resource Development, 2009a). Efforts are also underway, through the recently announced Saakshar Bharat scheme (2009-2012), to impart functional literacy and numeracy to those aged 15-35 who are non-literate and non-numerate, enable the neo-literate to continue their learning and acquire equivalency to formal education, and impart relevant skills to improve their earning capacities (Ministry of Human Resource Development, 2009c). Notably, the scheme does take note of the special needs of young people.

In the area of skill development, the National Skills Development Initiative aims to empower individuals through improved skills, knowledge and qualifications to gain access to employment in an increasingly competitive global market (Ministry of Labour, 2009). Objectives of the initiative are to create opportunities for skill acquisition, with special attention to youth, women and school drop-outs. To achieve these ambitious goals, public private partnerships are envisaged, and outreach is to be expanded through a variety of mechanisms including skill development centres at village and block levels, mobile training and distance learning programmes. At the same time, the coverage of vocations will be expanded and soft skills such as basic numeracy, literacy, rights, team work and confidence-building will be folded into vocational skill development curricula.

\section{Gaps}

With various schemes in place, as described earlier, enrolment in primary schools is near universal in the country. The number of rural habitations with at least one primary school has increased from 87 percent in 2002 to 99 percent in 2008 and those with upper primary schools within a radius of three $\mathrm{km}$ from 78 to 92 percent during the same period. Enrolment has increased for both boys and girls with a welcome narrowing of the gender gap. Similarly, the disparity between SCs/STs and the general population in this area has narrowed, though it has not been entirely eliminated (Planning Commission, 2011).

However, as the mid-term appraisal of the $\mathrm{XI}^{\text {th }}$ Plan observes, dropout rates remain high with as many as 43 percent of the children dropping out before completing elementary school. The quality of schooling is also a matter of concern (Planning Commission, 2011). A recent evaluation of basic competencies of students in Class VIII in rural areas reports that as many as one in six children could not read standard text books for Class II, one-third 
could not do simple calculations such as division, and about one-half could not perform simple tasks with regard to calculating area (Pratham Resource Centre, 2011). Further, little is known about the implementation of schemes such as RMSA; the mid-term appraisal of the $\mathrm{XI}^{\text {th }}$ Plan, however, notes that the implementation of programmes to promote secondary school education needs to be accelerated (Planning Commission, 2011). Similarly, while little is known about the implementation, reach and impact of efforts to enable young people to acquire marketable skills, available evidence indicates that there remains a huge unmet need for vocational skill building; although large proportions of youth -56 percent of young men and 68 percent of young women-were interested in acquiring vocational skills, just one-fifth of young men and one-quarter of young women had ever attended a vocational training programme (International Institute for Population Sciences and Population Council, 2010).

\section{Programmes that build a supportive environment}

In order to build a supportive environment to enable youth to obtain sexual and reproductive health information, seek counselling and services, and adopt safe practices, it is critical that communities, in general, and young people's gatekeepers, in particular, are sensitised to the unique needs of young people. Key gatekeepers include parents and parents-in-law, health care providers, teachers and other community-level functionaries, for example AWWs and organisers of SHGs. The National Adolescent Reproductive and Sexual Health Strategy proposes activities to reach a broad range of gatekeepers, including district officials, and members of panchayats, women's groups and civil society, with appropriate messages (Ministry of Health and Family Welfare, 2006a).

\section{Gaps}

Young people, in general, lack a safe and supportive environment, a limitation that is likely to pose major obstacles to their achievement of good sexual and reproductive health and the realisation of their sexual and reproductive rights. Parents and teachers often fail to serve as reliable sources of information for young people. Indeed, the Youth Study reports that just 10 percent of young people had received information on sexual matters from teachers and fewer than 10 percent of young men and women had discussed growing up or pregnancy- and reproduction-related matters with either of their parents (International Institute for Population Sciences and Population Council, 2010).

Programmatically, efforts to create a supportive environment for young people have been limited, including efforts on the ground to sensitise different gatekeepers. While the Implementation Guide for State and District Programme Managers has included parents in the target audience, the guide contains no discussion of the specific measures to be taken to involve parents or the special messages to be imparted to them (Ministry of Health and Family Welfare, 2006a). While there have been many more efforts to sensitise teachers, evaluations of their effectiveness are limited. Indeed, the discomfort experienced by teachers was a significant component of the backlash against the AEP. In-depth efforts that focus on training and building the aptitude of nodal teachers and helping them overcome their embarrassment and hesitation in discussing sexuality and reproductive health issues have traditionally been missing (United Nations Population Fund, 2003). Available research suggests that teachers are embarrassed about discussing sexual matters with adolescents, that they typically skip chapters relating to reproduction and, at best, discuss these issues in such technical terms that key areas of concern to 
youth remain unaddressed (Chakrabarti, 2003). It

is not clear that current training programmes have succeeded in changing teacher attitudes. Indeed, recent evaluations of NPEGEL and KGBV schemes have noted the inadequacy of gender sensitisation training and the orientation in adolescent issues given to teachers. The recent Rajya Sabha Report on the AEP highlights, moreover, the extent to which a supportive environment has not yet been created for the provision of sexual and reproductive health related messages even among the nation's political leadership (Rajya Sabha Committee on Petitions, 2009). 


\section{CHAPTER 5}

\section{Looking forward}

This overview has explored the major policies, laws and programmes related to the sexual and reproductive health of young people in India, and assessed the extent to which these efforts have responded to young people's needs. Findings suggest that although significant strides have been made in articulating a commitment to addressing many of the sexual and reproductive rights of young people, there remains a considerable schism between the commitments made in policies and programmes, the implementation of these commitments and the reality of young people's lives in India.

Our review has focused on six major programme thrust areas. The first was efforts to build awareness of sexual and reproductive health issues among young people. Our review shows that several programmes have been undertaken that attempt to reach a number of sub-populations of young people. While these programmatic initiatives are commendable, our review suggests that many remain poorly implemented, may not reach all groups of adolescents and youth, and little is known about their impact or quality. Of particular concern is the finding that out-of-school and married females may not be reached as they are unlikely to be members of clubs or mandals, or to have access to television programmes or telephone hotlines, and may not have the mobility or decision-making authority to attend group meetings in most settings. Given the backlash against information-providing programmes in certain states, moreover, awareness-building activities are likely to have been unevenly implemented across states as well. Finally, there appears to be little coordination in awareness-raising activities; as our review shows, activities have been conducted through the National AIDS Control Organisation and the Ministry of Health and Family Welfare, as well as through the activities of the Ministry of Human Resource Development, the Ministry of Women and Child Development, and the Ministry of Youth Affairs and Sports, aside from a host of programmes at the NGO level. In many cases, activities are conducted in parallel, curricula vary and responsibilities differ, emphasising the need for greater inter-sectoral coordination.

When we turn to our second thrust area, namely, delivery of and access to appropriate counselling and services, findings suggest that the reality falls far short of stated goals. There is considerable ambiguity in the extent of service delivery; for example, the unmarried-both females and males-effectively remain out of the purview of contraceptive services from the public sector at the community level, and no special efforts have been made to reach young people with voluntary counselling and testing, and condom promotion services. Indeed, the Adolescent Reproductive and Sexual Health Strategy and related orientation guides are inconsistent in describing the reach and content of the expanded services proposed. Moreover, the reach of these activities, where implemented, remains limited. Likewise, service provision under HIV/AIDS programmes tends to be generic, and delivery mechanisms for married and unmarried young women and men are identical to those available to the adult population. Although the need for provider reorientation and training is 
recognised and manuals have been prepared, few providers of all categories have been trained or oriented about the special service delivery needs of young people and the quality of training imparted remains questionable.

Clearly much more needs to be done, over the next decade, to put programme commitments into practice. Providers-be they outreach workers, or providers based at health centres, and counselling and testing facilities-will need special attention in order to enable them to overcome misgivings about delivering sensitive, non-judgmental, private and confidential services to young people. The roles and responsibilities of male health workers must be redefined to include sexual and reproductive health counselling and the provision of services to young men. Special efforts-home visits, in particular-must be made to enable those newlymarried young women and their husbands who wish to delay the first or subsequent pregnancies to access appropriate and regular contraceptive supplies, and, should pregnancy occur, to seek appropriate care. The establishment of regular adolescent health clinics at the PHC and $\mathrm{CHC}$ level need to be more carefully monitored and obstacles to their ability to attract young people addressed.

The third thrust area relates to programmes intended to reduce gender disparities and enhance the agency of girls and young women. Our review suggests a considerable commitment at programme level to offering opportunities to girls and young women, and to changing traditional gender role attitudes among young people as well as communities more generally. Again, however, as in the case of programmes intended to raise sexual and reproductive health awareness, curricula, messages and activities vary, and there is little coordination across the various sectors that implement programmes intended to foster gender equity among the young. Moreover, among programmes that have attempted to address these issues, little is known about the extent to which they have stressed sexual and reproductive rights or ways of building egalitarian relations among young couples, measures that would clearly have implications for sexual and reproductive health and care-seeking. Besides, programmes have not been systematically assessed in terms of their impact on reducing gender disparities, or in changing gender inegalitarian attitudes, sensitising youth and their gatekeepers about the sexual and reproductive rights of women and men, or changing the perceptions of young men.

The fourth thrust area relates to programmes focused on improving the nutritional status of adolescent girls. As we have seen, frequent changes in nutritional programmes, combined with limited reach and inconsistent financial support, have resulted in little measurable effect of the programme in improving the weight of adolescent girls. The recently launched SABLA programme is expected to overcome these limitations and efforts must be made to monitor its implementation and its effect on adolescent anaemia and weight gain.

The fifth thrust area relates to programmes that enable young people to acquire higher educational levels and relevant marketable skills. While significant strides have been made in this area, the current efforts fall short of what is required to enable the country to harness its demographic dividend and its youth to participate in and benefit from global development.

The sixth thrust area of policies and programmes has been on creating a supportive environment for young people. Despite the fact that programmes have noted the importance of sensitising gatekeepers, efforts in this regard have been limited in terms of the number of activities undertaken, the kinds of gatekeepers addressed and the extent to which 
programme content is intended to orient gatekeepers to young people's needs or to enable gatekeepers to overcome their own discomfort and misconceptions in discussing sexual and reproductive health matters with young people. Parents are rarely included in gatekeeper programmes, although the importance of parent-child communication has been frequently stressed. Teacher training too has not succeeded in enabling teachers to overcome their own embarrassment in dealing with these issues. And given the recent uproar in political circles, there is a need to sensitise policy makers and elected officials as well. In short, efforts to build a supportive environment to meet young people's needs have yet to be undertaken in a sustained way and among all gatekeepers.

Overriding all of these concerns is the need for greater inter-sectoral coordination with regard to programming for young people. Young people have multifaceted needs-for services, information and counselling, communication and negotiation skill building, programmes that foster gender equity/ develop egalitarian gender norms, and access to supportive gate-keepers, for example. Many of these need and have been addressed in the programmes of several Ministries and Departments-Health and Family Welfare and the National AIDS Control Organisation, Human Resource Development and Education, Women and Child Development and Youth Affairs and Sports, in particular. While efforts have been made to establish a nodal authority to coordinate work on young people, this has not been effectively accomplished, and as a result, as apparent from this review, coordination is not always evident. Efforts are needed to establish such a coordinating mechanism and ongoing efforts in the Ministry of Health and Family Welfare to establish a coordination cell and/or dedicated division on adolescent health need to be fast tracked.

In conclusion, our review clearly shows that there is considerable recognition of the importance of young people in defining India's future, and a considerable commitment to meeting their needs, including those in the sexual and reproductive health and rights arenas. Efforts have been initiated to translate this commitment into practice. Policies and programmes - be they related to women and child development, young people, health and family welfare, or HIV/AIDS— have all recognised the importance of improving sexual and reproductive health and choice among young people, and the importance of healthy, productive young women and men in shaping India's future. However, implementation challenges abound and it is not clear that activities have been implemented according to the spirit of each programme. Moreover, monitoring and evaluation has been so sporadic that it is not clear how many young people have been reached, the quality of their interactions with programmes or the extent to which programmes have indeed affected their sexual and reproductive health, awareness, and exercise of informed choices. What is needed is a commitment to ensuring that programmes do indeed reach young people, that the scope and content of programmes are expanded, and that promising lessons are assimilated and scaled up. 


\section{References}

Centre for Development and Population Activities (CEDPA). 2011. Udaan Towards A Better Future: Improving the Lives of Young People in Jharkhand, India. New Delhi: CEDPA.

Chakrabarti, V. 2003. "Population education in formal and non-formal sectors in India," in Towards Adulthood: Exploring the Sexual and Reproductive Health of Adolescents in South Asia, ed. S. Bott et al. Geneva: World Health Organisation.

Chhabra, R., S.N. Gupte, A. Mehta and A. Shande. 1988. "MTP and concurrent contraceptive adoption in rural India," Studies in Family Planning, 19(4):244-247.

Centre for Operations Research and Training (CORT). 2009. Assessment of Adolescent Reproductive and Sexual Health (ARSH) Centers in Gujarat. CORT: Vadodara.

Ganatra, B. 2000. "Abortion research in India: What we know and what we need to know," in Women's Reproductive Health in India, eds. R. Ramasubban and S. Jejeebhoy. Jaipur: Rawat Publications.

Ganatra, B. and S. Hirve. 2002. "Induced abortions among adolescent women in rural Maharashtra," Reproductive Health Matters, 10(19):76-85.

Gonsalves, C. 2007. Illegal yet Valid! Accessed on 21 July 2011 at http://www.hrln.org/admin/issue/subpdf/Illegal_ yet_valid_2007.pdf.

Government of India (GOI). 1971. The Medical Termination of Pregnancy Act (Act. No. 34). New Delhi: Government of India.

Institute of Health Management Research (IIHMR). 2010. Evaluation Study on Adolescent-Friendly Health Clinics in Maharashtra. IIHMR: Jaipur.

International Institute for Population Sciences (IIPS) and Macro International. 2007. National Family Health Survey (NFHS-3), India, 2005-06. Mumbai: IIPS.

International Institute for Population Sciences (IIPS) and Population Council. 2010. Youth in India: Situation and Needs 2006-2007. Mumbai: IIPS.

Jaya, J. 2010. "Responding to the sexuality education controversy in India." Paper presented at the International Consultation on Comprehensive Sexuality Education: Advancing Human Rights, Gender Equality and Improved Sexual and Reproductive Health: Review of Current Evidence and Experiences, Bogota, Colombia.

Jaya, J. and S. Yadav. 2010. "Adolescence education programme: evolution, implementation status and lessons learned." Paper presented at the Second UNFPA Regional Wokshop on Programming for Young People: The Framework for Action, Kathmandu, Nepal.

Jejeebhoy, S.J., S. Kalyanwala, A.J. Francis Zavier et al. 2010. "Experience seeking abortion among unmarried young women in Bihar and Jharkhand, India: delays and disadvantages," Reproductive Health Matters, 18(35):163-174. 
Jejeebhoy, S.J., A.J. Francis Zavier, R. Acharya et al. 2011a. Increasing access to safe abortion in rural Maharashtra: Outcomes of a Comprehensive Abortion Care Model. New Delhi: Population Council.

Jejeebhoy, S.J., A.J. Francis Zavier, R. Acharya et al. 2011b. Increasing access to safe abortion in rural Rajasthan: Outcomes of a Comprehensive Abortion Care Model. New Delhi: Population Council.

Lal, S. and D. Paul. 2003. "Towards universalization of integrated child development services (ICDS)," Indian Journal of Community Medicine, 28(4):147-152.

Law Commission of India. 2008. Proposal to Amend the Prohibition of Child Marriage Act, 2006 and Other Allied Laws (Report No.205). New Delhi: Law Commission of India, Government of India.

Lim, S.S., L. Dandona, J.A. Hoisington et al. 2010. "India’s Janani Suraksha Yojana, a conditional cash transfer programme to increase births in health facilities: An impact evaluation," The Lancet, 375:2009-23.

Ministry of Health and Family Welfare (MOHFW). 2000. National Population Policy 2000. New Delhi: MOHFW, Government of India.

Ministry of Health and Family Welfare (MOHFW). 2002. National Health Policy. New Delhi: MOHFW, Government of India.

Ministry of Health and Family Welfare (MOHFW). 2005. RCH Phase II: National Programme Implementation Plan. New Delhi: MOHFW, Government of India.

Ministry of Health and Family Welfare (MOHFW). 2006a. Implementation Guide on RCH II: Adolescent Reproductive Sexual Health Strategy, for State and District Programme Managers. New Delhi: MOHFW, Government of India.

Ministry of Health and Family Welfare (MOHFW). 2006b. Orientation Programme for Medical Officers to Provide Adolescent-Friendly Reproductive and Sexual Health Services: Facilitator's Guide. New Delhi: MOHFW, Government of India.

Ministry of Health and Family Welfare (MOHFW). 2006c. Orientation Programme for ANMs/LHVs to Provide Adolescent-Friendly Reproductive and Sexual Health Services: Facilitator's Guide. New Delhi: MOHFW, Government of India.

Ministry of Health and Family Welfare (MOHFW). 2006d. Reading material for ASHA, Book \# 3, Family planning, RTI/STIs and HIVIAIDS and ARSH. New Delhi: MOHFW, Government of India. Accessed on 4 July 2011 at http://www.mohfw.nic.in/NRHM/Documents/ASHA_Book_No_3.pdf.

Ministry of Health and Family Welfare (MOHFW). 2006e. Janani Suraksha Yojana: Features and Frequently Asked Questions and Answers. New Delhi: MOHFW, Government of India. Accessed on 25 July 2011 at http://mohfw. nic.in/WriteReadData/1892s/file28-99526408.pdf.

Ministry of Health and Family Welfare (MOHFW). 2009a. Reproductive and Sexual Health of Young People in India. New Delhi: MOHFW, Government of India.

Ministry of Health and Family Welfare (MOHFW). 2009b. National Rural Health Mission, Reproductive and Child Health Program Phase 2, $\sigma^{\text {th }}$ Joint Review Mission Aide Memoire. New Delhi: MOHFW, Government of India.

Ministry of Health and Family Welfare (MOHFW). 2010. Asha Module 6: Skills that Save Lives. New Delhi: MOHFW, Government of India.

Ministry of Health and Family Welfare (MOHFW). n.d. School Health Programme. New Delhi: MOHFW, Government of India. Accessed on 25 July 2011 at http://www.mohfw.nic.in/WriteReadData/ 1892s/4536157059file6.pdf. 
Ministry of Human Resource Development (MOHRD). 1998. National Policy on Education 1986 (as modified in 1992) with National Policy on Education, 1968. New Delhi: MOHRD, Government of India.

Ministry of Human Resource Development (MOHRD). 2008a. Selected Educational Statistics 2007-08. New Delhi: MOHRD, Government of India.

Ministry of Human Resource Development (MOHRD). 2008b. First Joint Review Mission of Mabila Samakhya, Aide Memoire. New Delhi: MOHRD, Government of India.

Ministry of Human Resource Development (MOHRD). 2008c. KGBV (Kasturba Gandhi Balika Vidyalaya) and NPEGEL (National Programme for Education of Girls at the Elementary Level) Evaluation Report, February 2008. New Delhi: MOHRD, Government of India. Accessed on 22 July 2011 at http://ssa.nic.in/research-studies/ KGBV-NPEGEL Evaluation Report Feb2008.zip/view.

Ministry of Human Resource Development (MOHRD). 2009a. Framework for implementation of Rashtriya Madhyamik Shiksha Abhiyan. New Delhi: MOHRD, Government of India. Accessed on 4 July 2011 at http:// education.nic.in/secedu/Framework_Final_RMSA.pdf.

Ministry of Human Resource Development (MOHRD). 2009b. Sarva Shiksha Abhiyan, Status of Physical Progress on NPEGEL as on 15th July 2010. New Delhi: MOHRD, Government of India. Accessed on 22 July 2011 at http://ssa.nic.in/girls-education/npegel/NPEGEL_progress_18July07.pdf/view.

Ministry of Human Resource Development (MOHRD). 2009c. Saakshar Bharat. New Delhi: MOHRD, Government of India. Accessed on 02 December 2009 at http://education.nic.in/Elementary/SaaksharBharat.pdf.

Ministry of Human Resource Development (MOHRD). 2011. The Right of Children to free and Compulsory Education Act, 2009. The Gazette of India: Extraordinary, published on March 24, 2011. New Delhi: MOHRD, Government of India.

Ministry of Labour. 2009. National Policy on Skill Development. New Delhi: Ministry of Labour, Government of India. Accessed on 4 July 2011 at http://www.labour.nic.in/policy/NationalSkillDevelopmentPolicyMar09.pdf.

Ministry of Law and Justice. 2007. The Prohibition of Child Marriage Act, 2006. No. 6 of 2007 Gazette of India. New Delhi: Ministry of Law and Justice, Government of India. Accessed on 1 June 2011 at http://www.wcd.nic. in/cma2006.pdf.

Ministry of Women and Child Development (MOWCD). 2001. National Policy for the Empowerment of Women. New Delhi: MOWCD, Government of India.

Ministry of Women and Child Development (MOWCD). 2002. Swadhar, A Scheme for A Scheme for Women in Difficult Circumstances. New Delhi: MOWCD, Government of India. Accessed on 22 July 2011 at http://wcd.nic. in/revisedswadhar.htm.

Ministry of Women and Child Development (MOWCD). 2005. National Plan of Action for Children 2005. New Delhi: MOWCD, Government of India.

Ministry of Women and Child Development (MOWCD). 2006a. Protection of Women from Domestic Violence Act, 2005 (43 of 2005) the Gazette of India: Extraordinary. New Delhi: MOWCD, Government of India.

Ministry of Women and Child Development (MOWCD). 2006b. The Immoral Traffic (Prevention) Amendment Bill, 2006, Bill No. 47 of 2006. New Delhi: MOWCD, Government of India. 
Ministry of Women and Child Development (MOWCD). 2007. UJJAWALA-A Comprehensive Scheme for Prevention of Trafficking and Rescue, Rehabilitation and Re-Integration of Victims of Trafficking for Commercial Sexual Exploitation. New Delhi: MOWCD, Government of India. Accessed on 22 July 2011 at http://wcd.nic.in/ schemes/ujjawala.pdf.

Ministry of Women and Child Development. (MOWCD). 2010a. Implementation Plan of Rajiv Gandhi Scheme for Empowerment of Adolescent Girls (RGSEAG) SABLA. Agenda No. 3. New Delhi: MOWCD, Government of India. Accessed on 25 July 2011 at http://wcd.nic.in/agenda16062010/agenda_16062010_item3.pdf.

Ministry of Women and Child Development (MOWCD). 2010b. Annual Report 2009-10. New Delhi: MOWCD, Government of India.

Ministry of Women and Child Development (MOWCD). 2010c. State-wise Funds Released/Utilised under KSY (Kishori Shakti Yojana) in 2006-07, 2007-08, 2008-09 and Funds Released. New Delhi: MOWCD, Government of India. Accessed on 22 July 2011 at http://wcd.nic.in/icdsimg/ksy06-10.htm.

Ministry of Women and Child Development (MOWCD). 2010d. State-wise Funds Released/Utilized during last 3 years under Nutrition Programme for Adolescent Girls (NPAG) (2006-07, 2007-08, 2008-09). New Delhi: MOWCD, Government of India. Accessed on 22 July 2011 at http://wcd.nic.in/icdsimg/npag2006-09.htm.

Ministry of Women and Child Development (MOWCD). 2011. The Protection of Children from Sexual Offences Bill, 2011. New Delhi: MOWCD, Government of India. Accessed on 22 July, 2011 at, http://wcd.nic.in/act/ protectionbill.pdf.

Ministry of Youth Affairs and Sports (MOYAS). 2003. National Youth Policy 2003. New Delhi: MOYAS, Government of India.

Ministry of Youth Affairs and Sports (MOYAS). 2011. Annual Report 2010-2011. New Delhi: MOYAS, Government of India.

Ministry of Youth Affairs and Sports (MOYAS). n.d. National Programme for Youth and Adolescent Development: Scheme Guidelines. New Delhi: MOYAS, Government of India. Accessed on 4 July 2011 at http://www.yas.nic.in/ writereaddata/linkimages/5349309212.pdf.

National AIDS Control Organisation (NACO) 2002. National AIDS Prevention and Control Policy. New Delhi: NACO.

National AIDS Control Organisation (NACO). 2004. Annual Report 2002-2004. New Delhi: NACO.

National AIDS Control Organisation (NACO). 2006. National AIDS Control Programme, Phase III (2006-2011), Strategy and Implementation Plan. New Delhi: NACO.

National AIDS Control Organisation (NACO). 2008a. Adolescence Education Programme, Life Skills Development. New Delhi: NACO. Accessed on 25 July 2011 at http://www.nacoonline.org/upload/NACOinActiion/AEP\%20 -\%20Teachers\%20Workbook.pdf.

National AIDS Control Organisation (NACO). 2008b. Adolescence Education Programme, Life Skills Development: Facilitators' Guide. New Delhi: NACO. Accessed on 10 March 2011 at http://www.nacoonline.org/upload/ NACOinActiion/FacilitatorsGuide.pdf.

National AIDS Control Organisation (NACO). 2009. Project Directors' Review Meeting, September 01, 2009. New Delhi: NACO. Accessed on 25 July 2011 at http://www.nacoonline.org/upload/Meetings_conferences_Workshops/ Minutes\%20of\%20\%20PDs\%20review\%20meeting\%20on\%201st\%20Sept09\%20Final\%208.8.2k9.pdf and http://www.nacoonline.org/upload/Meetings_conferences_Workshops/PDreview. 
National AIDS Control Organisation (NACO). 2010. Annual Report 2009-10. New Delhi: NACO.

National AIDS Control Organisation (NACO). n.d. Adolescence Education Programme. New Delhi: NACO. Accessed on 10 March 2011 at http://nacoonline.org/Quick_Links/Youth/School_Age_Education_Program_SAEP.

Narayan, G. and J. Jaya. 2011. "Strategy for reaching adolescents in out-of-school settings through Nehru Yuva Kendra Sangathan (NYKS) in collaboration with Ministry of Youth Affairs and Sports (MOYAS).” Presentation made to the Joint Secretary, Ministry of Youth Affairs and Sports, New Delhi.

National Crime Records Bureau (NCRB). 2010. Crime in India 2009. New Delhi: NCRB, Government of India.

National Council of Educational Research and Training (NCERT). 2005. National Curriculum Framework 2005. New Delhi: NCERT.

National Council of Educational Research and Training (NCERT). 2011. Training and Resource Materials under the Adolescence Education Programme. New Delhi: NCERT.Accessed on 4 July 2011 at http://www.ncert.nic.in/ programmes/aep/aep.html.

National Commission for Protection of Child Rights (NCPCR). n.d. Mandate of the National Commission for Protection of Child Rights. New Delhi: NCPCR. Accessed on 22 July at http://www.ncpcr.gov.in/mandate_ commission.htm.

Nutrition Foundation of India. 2006. Report of Evaluation of National Programme for Adolescent Girls. New Delhi: Nutrition Foundation of India.

Office of the Registrar General and Census Commissioner, India. 2006. Population Projections for India and States 2001-2026 (Revised December 2006). New Delhi: Office of the Registrar General and Census Commissioner, India.

Office of the Registrar General, India. 2011. Special Bulletin on Maternal Mortality in India 2007-09. New Delhi: Office of Registrar General, India.

Parasuraman, S., S. Kishor, S.K. Singh and Y. Vaideshi. 2009. A Profile of Youth in India, National Family Health Survey (NFHS-3), India, 2006-06. Mumbai: IIPS.

Press Information Bureau (PIB). 2010. Integrated Child Protection Scheme (ICPS). New Delhi: Press Information Bureau, Government of India. Accessed on 22 July, 2011 at http://pib.nic.in/newsite/erelease.aspx? relid=67659.

Planning Commission. 2008a. Eleventh Five Year Plan 2007-2012: Inclusive Growth. Vol. 1. New Delhi: Government of India.

Planning Commission. 2008b. Eleventh Five Year Plan (2007-12, Volume II, Social Sector. New Delhi: Government of India.

Planning Commission. 2011. Mid-Term Appraisal Eleventh Five Year Plan 2007-2012. New Delhi: Oxford University Press.

Pratham Resource Centre. 2011. Annual Status of Education Report (Rural) 2010. Mumbai: Pratham Resource Centre.

Rajya Sabha Committee on Petitions. 2009. Hundred and thirty-fifth report on petition praying for national debate and evolving consensus on the implementation of the policy for the introduction of sex education in the schools and holding back its introduction until then. New Delhi: Rajya Sabha, Parliament of India. Accessed on 25 July 2011 at http://164.100.47.5:8080/newcommittee/reports/EnglishCommittees/Committee\%20on\%20Petitions/135\%20 Report.htm. 
Rajiv Gandhi National Institute of Youth Development (RGNIYD). 2010. National Youth Policy 2010 (first draft). Sriperumbudur: RGNIYD. Accessed on 04 July 2011 at http://www.rgniyd.gov.in/resource/Draft\%20NYP\%20 10.12.2010.pdf.

Santhya, K.G. and S.J. Jejeebhoy. 2007. "Young People’s Sexual and Reproductive Health in India: Policies, Programmes and Realities," Regional Working Paper \#19, New Delhi: Population Council.

Santhya, K.G., S.J. Jejeebhoy and S. Ghosh. 2007. Addressing the Sexual and Reproductive Health Needs of Young People: Perspectives and Experiences of Stakeholders from the Health and Non-health Sectors. New Delhi: Population Council.

Santhya, K.G., R. Acharya and S.J. Jejeebhoy. 2011a. "Condom use before marriage and its correlates: Evidence from India." International Perspectives on Sexual and Reproductive Health (forthcoming).

Santhya, K.G., S.J. Jejeebhoy, R. Acharya et al. 2011b. Effects of the Janani Suraksha Yojana on maternal and newborn care practices: Women's experience in Rajasthan. New Delhi: Population Council.

Santhya, K.G. 2011c. Implementing the JSY Programme: Perspectives and experiences of ASHA's in Rajasthan (forthcoming report).

Sekher, T.V. 2010. Special Financial Incentive Schemes for the Girl Child in India: A Review of Select Schemes. Mumbai: IIPS.

Solapurkar, M.L. and R.N. Sangam. 1985. "Has the MTP Act in India proved beneficial?" Journal of Family Welfare, 31(3):46-52.

Sujay, R. 2009. "Premarital sexual behaviour amongst unmarried college students of Gujarat, India," Health and Population Innovation Fellowship Programme Working Paper No. 9. New Delhi: Population Council.

United Nations Population Fund (UNFPA). 2003. UNFPA-Supported Project for Adolescents during the UNFPA Fifth Country Programme (1997-2002): A Compendium. New Delhi: UNFPA. 


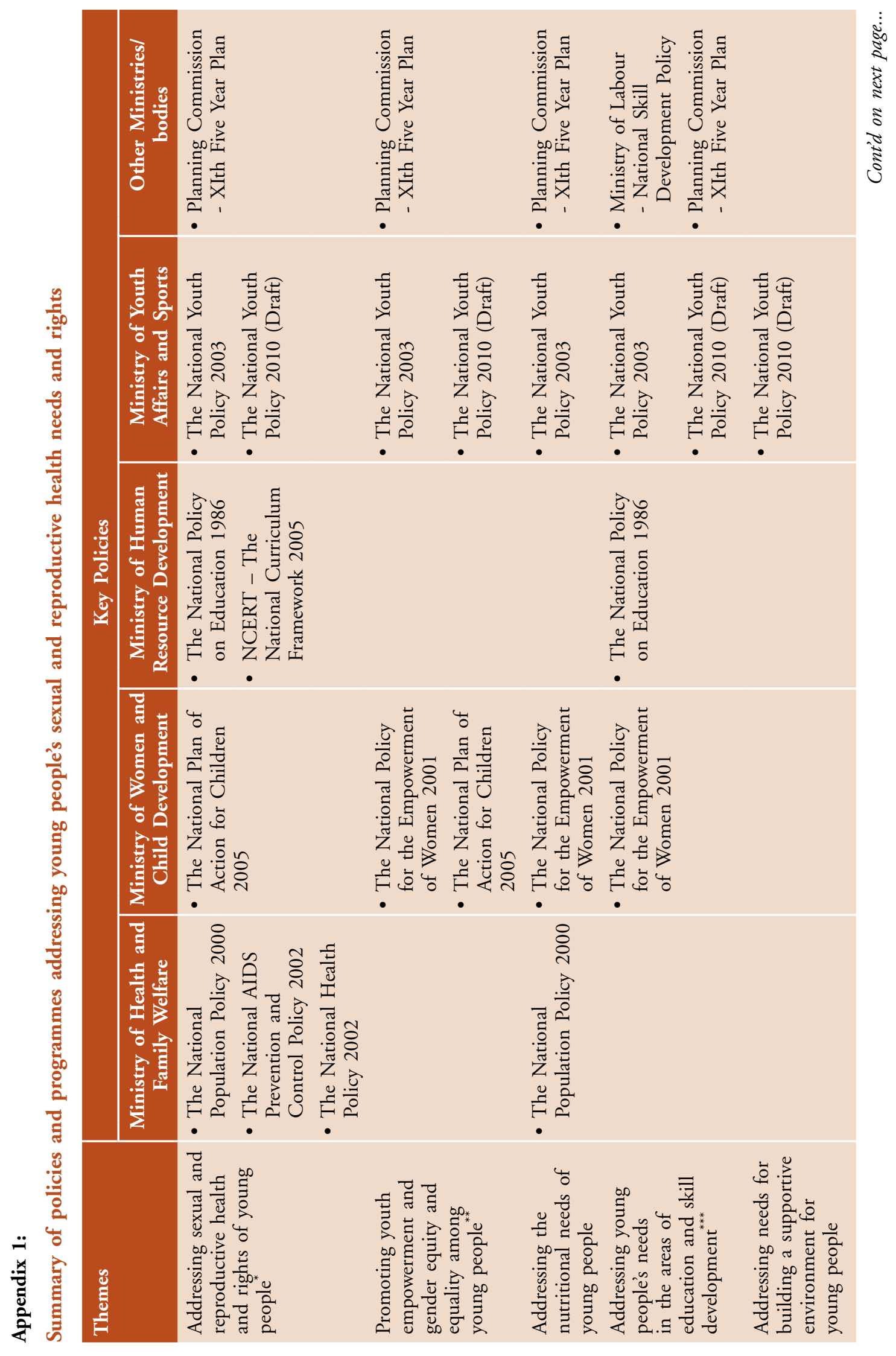




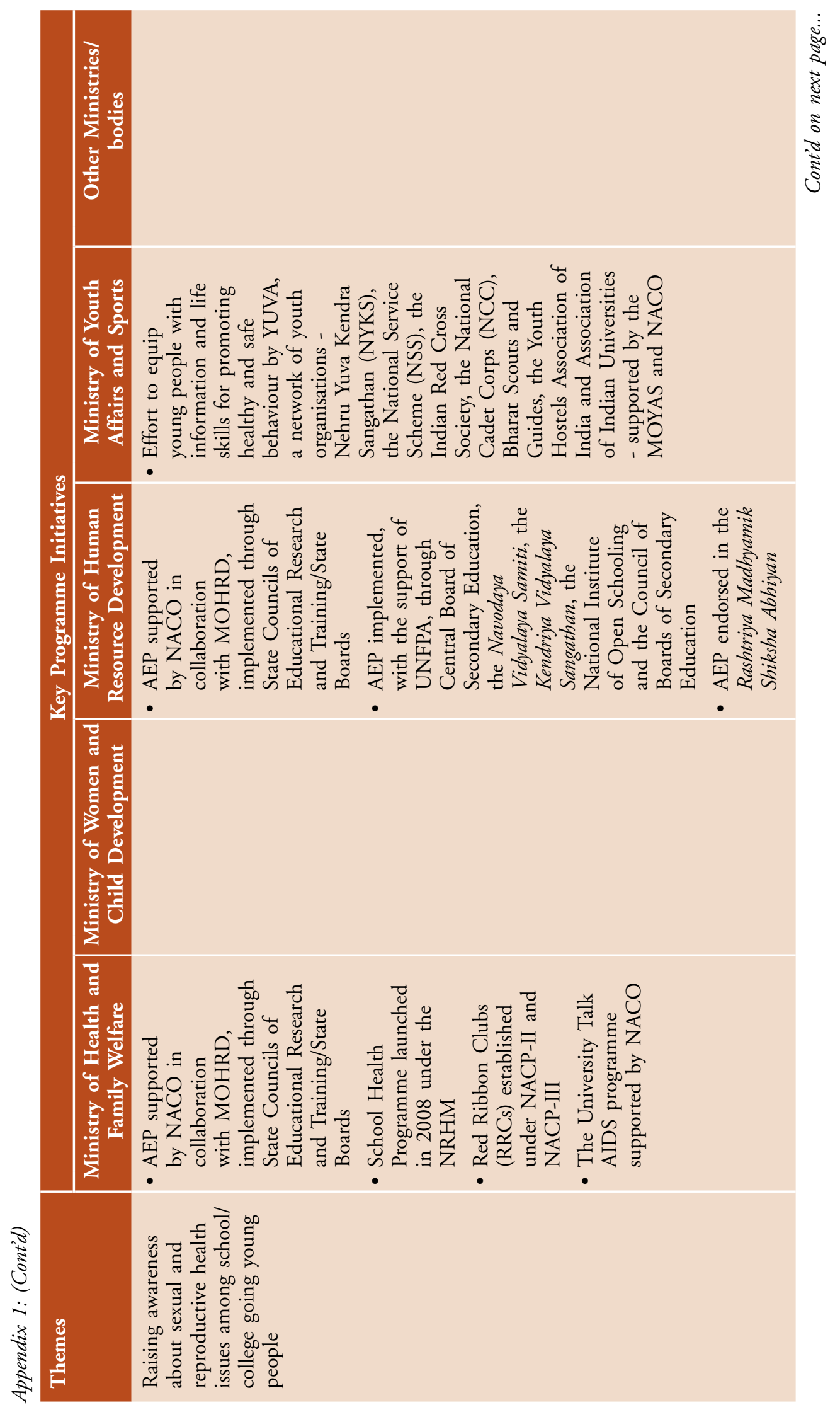




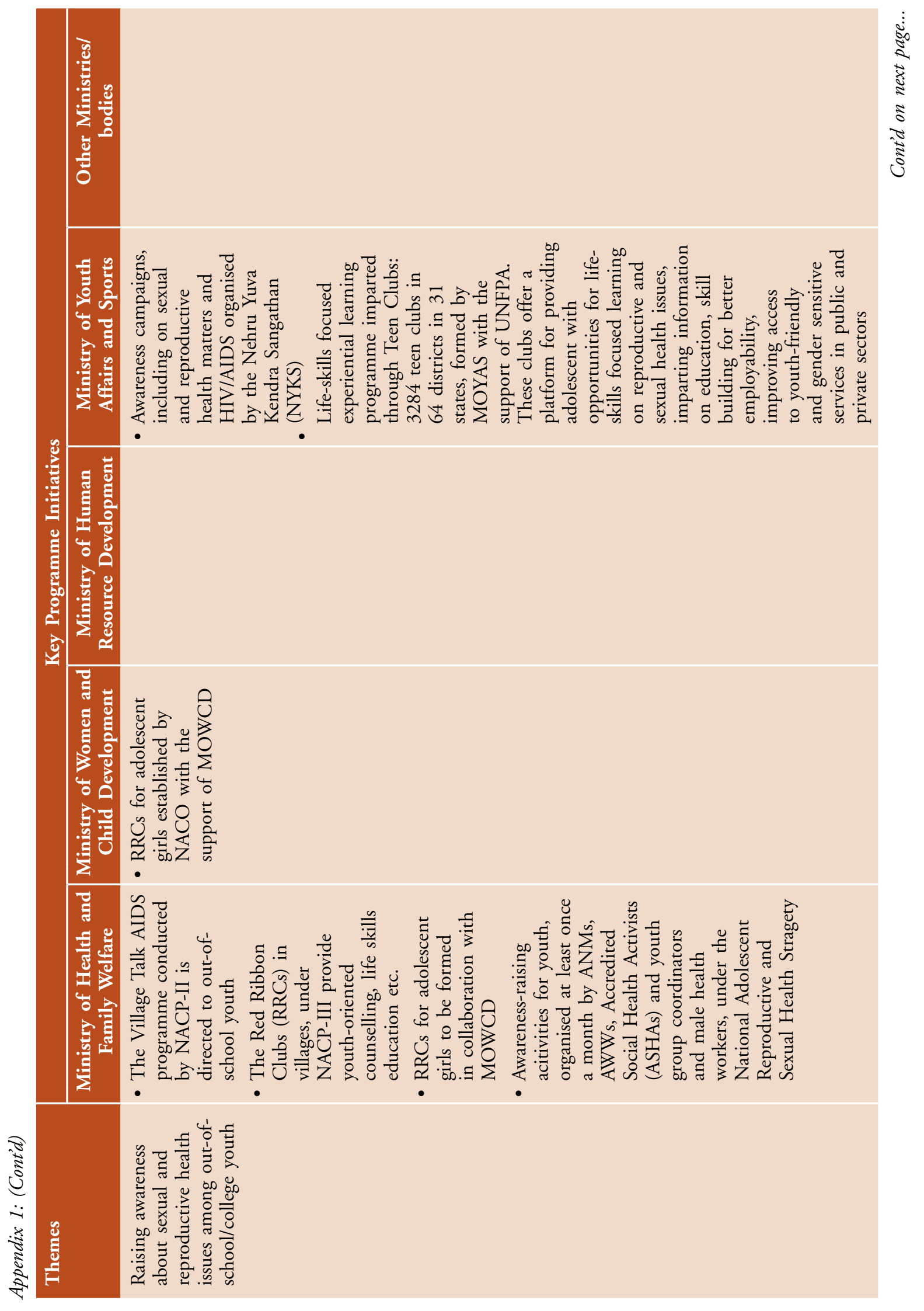




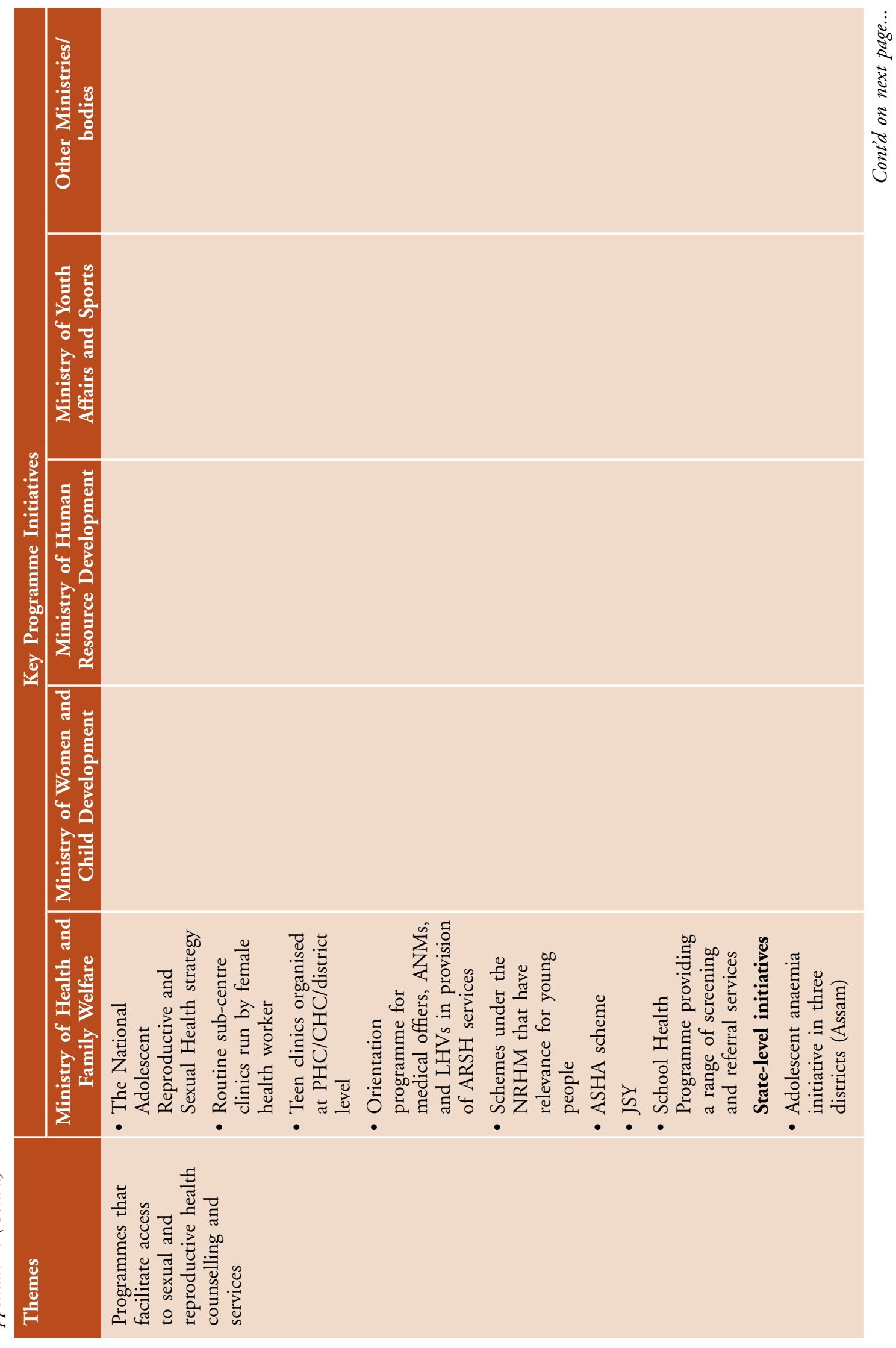




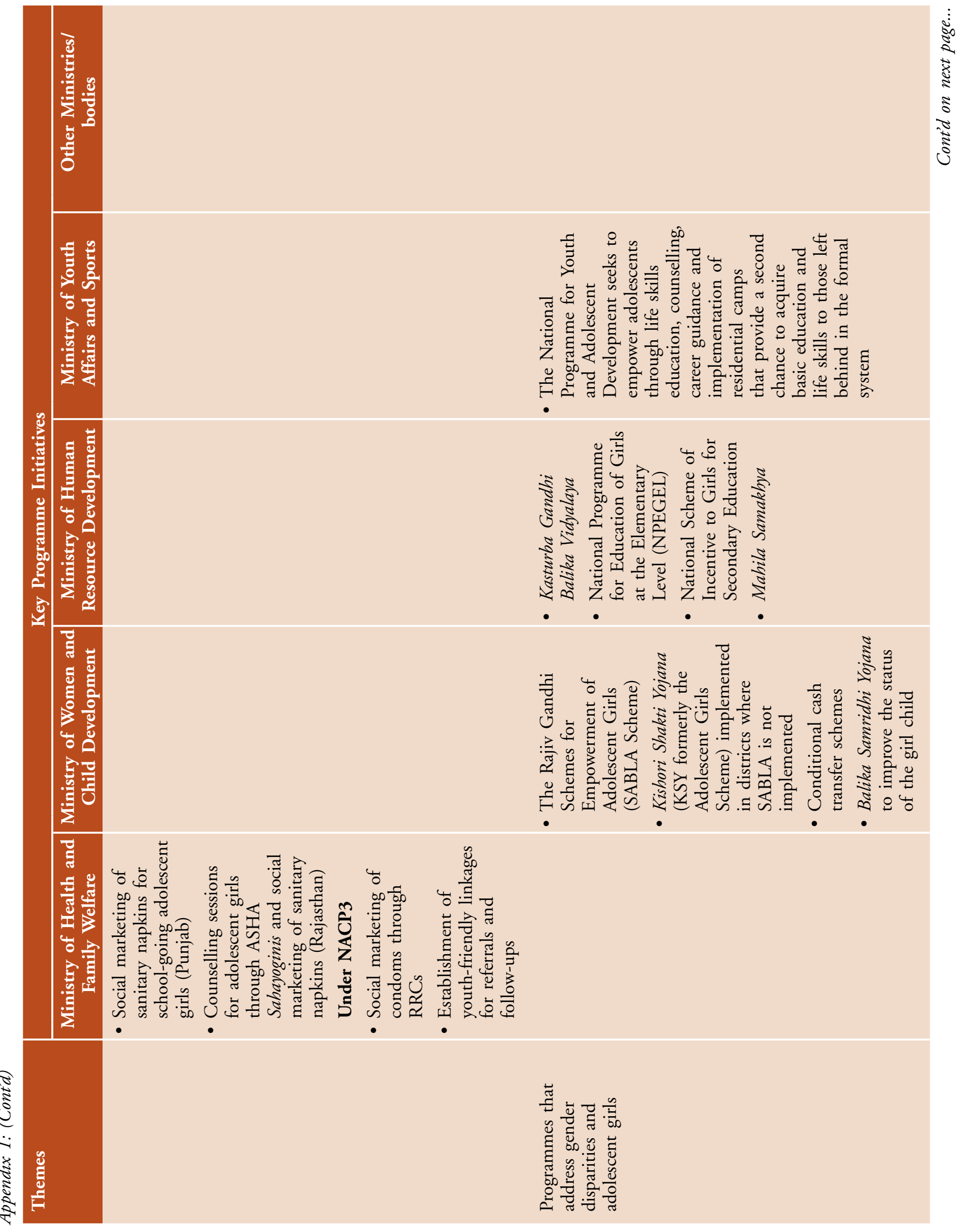




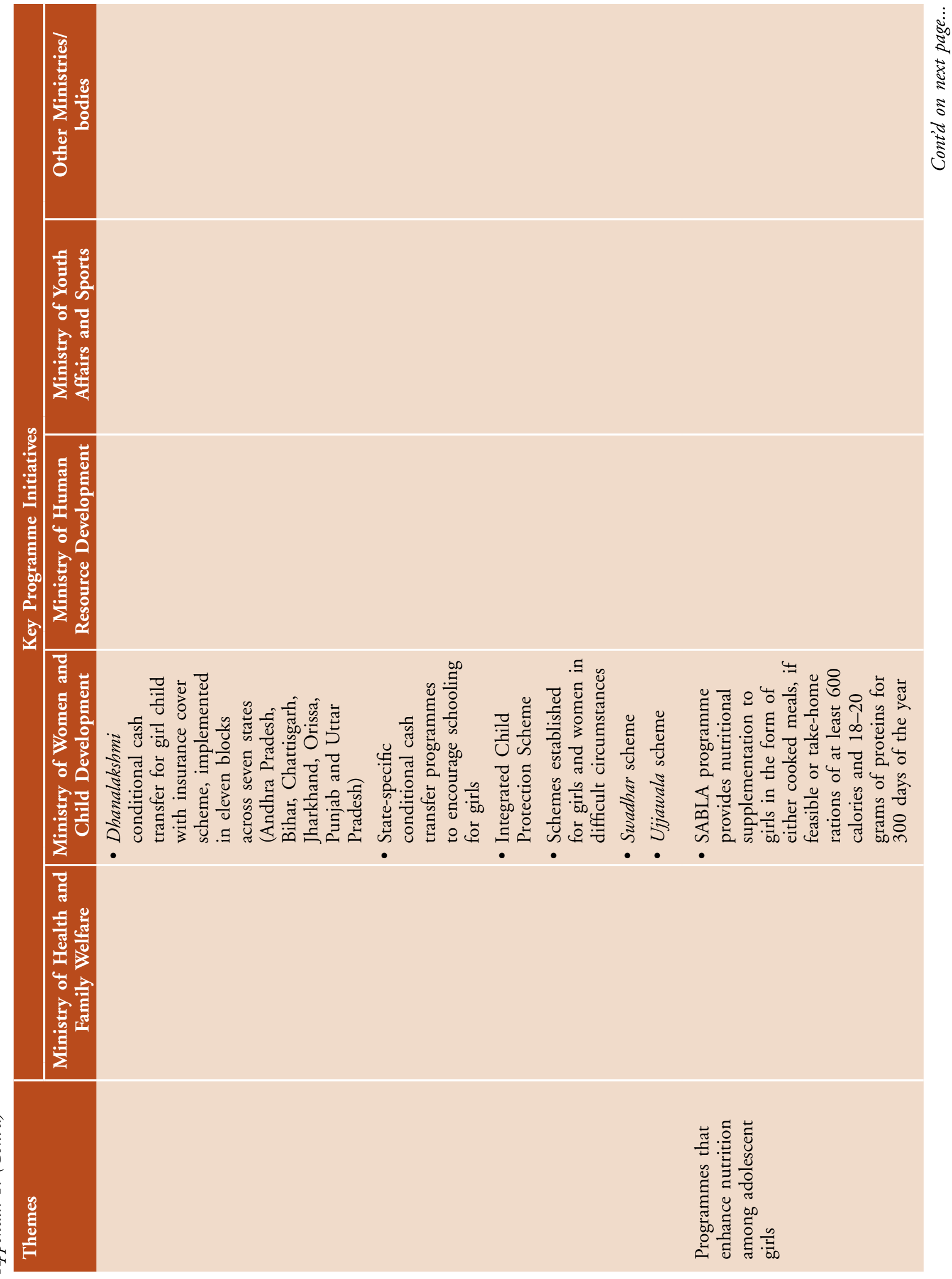




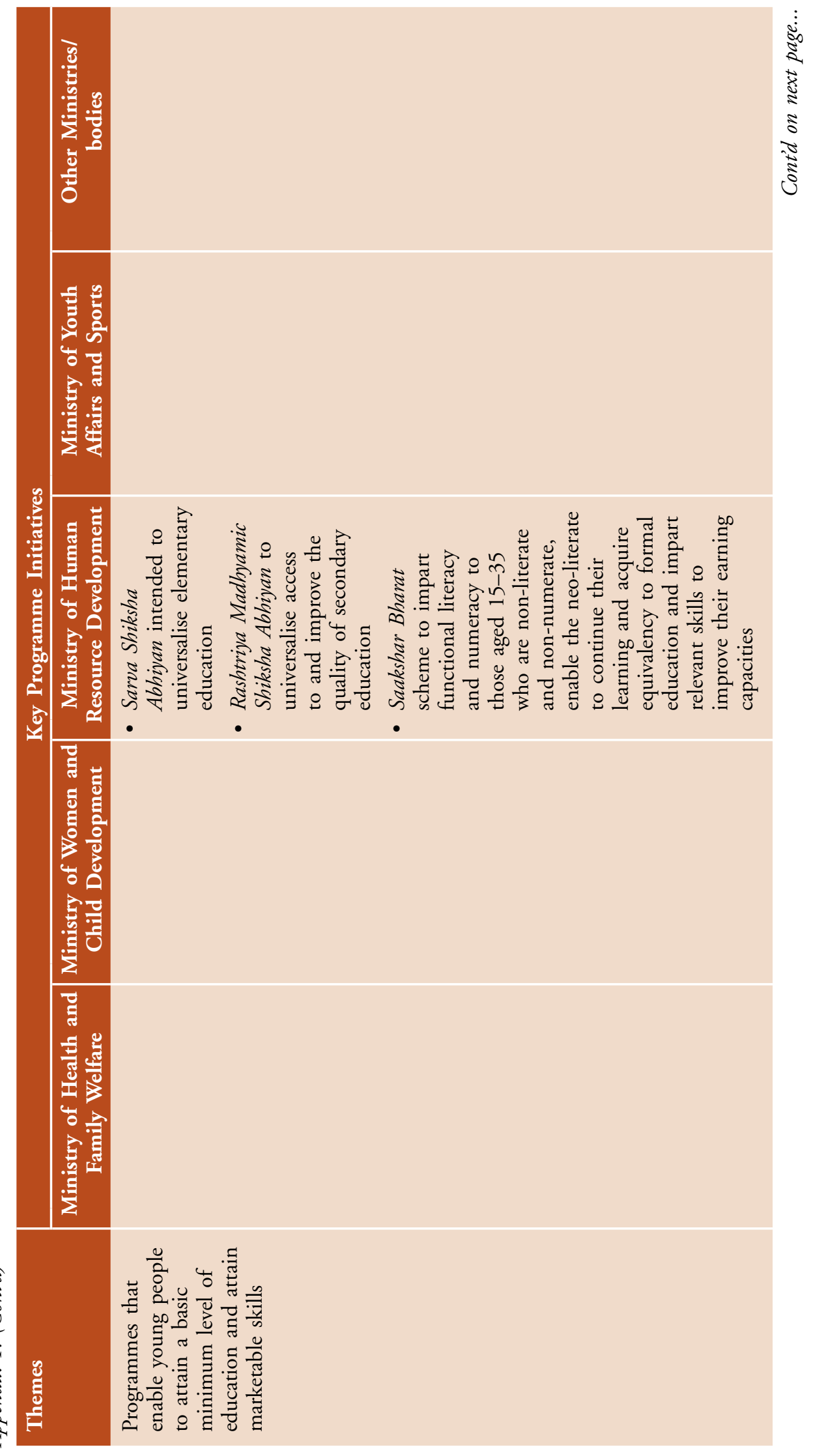




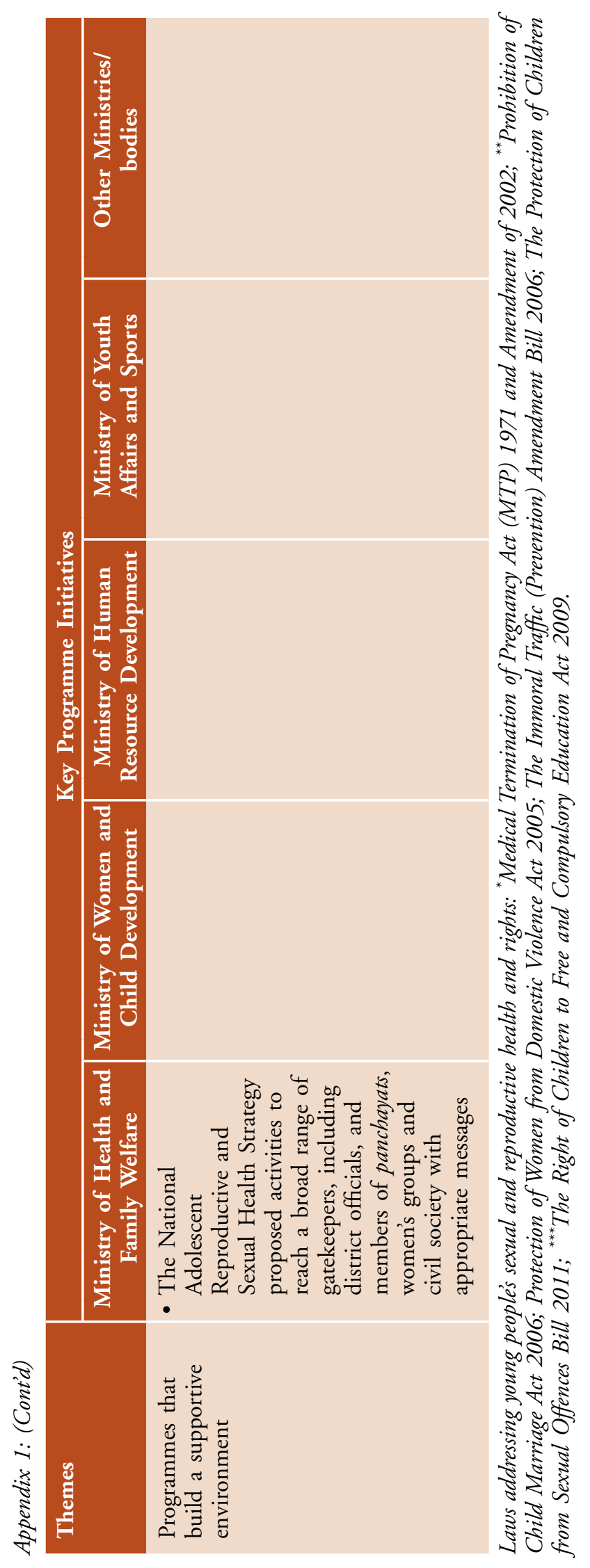




\section{Authors}

Shireen J Jejeebhoy, Senior Associate, Population Council, New Delhi

K G Santhya, Associate II, Population Council, New Delhi 

(P Population Council

Zone 5-A, Ground Floor India Habitat Centre

Lodi Road

New Delhi 110 003, India 